\title{
Graphene/sol-gel modified polyurethane coating for wind turbine blade leading edge protection: Properties and performance
}

Dashtkar, Arash; Johansen, Nicolai Frost-Jensen; Mishnaevsky, Leon; Williams, Neil A.; Hasan, Shadi W.; Wadi, Vijay S.; Silvello, Alessio; Hadavinia, Homayoun

\section{Published in:}

Polymers and Polymer Composites

Link to article, DOI:

$10.1177 / 09673911221074197$

Publication date:

2022

Document Version

Publisher's PDF, also known as Version of record

Link back to DTU Orbit

Citation (APA):

Dashtkar, A., Johansen, N. F-J., Mishnaevsky, L., Williams, N. A., Hasan, S. W., Wadi, V. S., Silvello, A., \& Hadavinia, H. (2022). Graphene/sol-gel modified polyurethane coating for wind turbine blade leading edge protection: Properties and performance. Polymers and Polymer Composites, 30, [096739112210741]. https://doi.org/10.1177/09673911221074197

\section{General rights}

Copyright and moral rights for the publications made accessible in the public portal are retained by the authors and/or other copyright owners and it is a condition of accessing publications that users recognise and abide by the legal requirements associated with these rights.

- Users may download and print one copy of any publication from the public portal for the purpose of private study or research.

- You may not further distribute the material or use it for any profit-making activity or commercial gain

- You may freely distribute the URL identifying the publication in the public portal 


\title{
Graphene/sol-gel modified polyurethane coating for wind turbine blade leading edge protection: Properties and performance
}

\author{
Arash Dashtkar', Nicolai Frost-Jensen Johansen ${ }^{2}{ }^{(0}$, Leon Mishnaevsky Jr. ${ }^{2}$, \\ Neil A Williams', Shadi W Hasan ${ }^{3}$, Vijay S Wadi ${ }^{3}$, Alessio Silvello ${ }^{4}$ and \\ Homayoun Hadavinia' (1)
}

\begin{abstract}
The development of two novel elastomeric erosion resistant coatings for the protection of wind turbine blades is presented. The coatings are prepared by modifying polyurethane (PU) with (i) hydroxyl functionalised graphene nanoparticles (f-GNP) and (ii) f-GNP and a hydrophobic silica-based sol-gel (SG). Tensile, monotonic and cyclic compression and tearing tests have been conducted on the neat PU and the two newly developed elastomeric PU nanocomposites (PU + GNP and PU + GNP + SG) to allow their properties to be compared. The test results showed that the mechanical properties of PU and the modified PUs have strong dependency on temperature, strain rate and nanoparticles loading and addition of GNP and SG to PU improved the mechanical properties. Compared to PU, Young's modulus and modulus of toughness of PU + GNP + SG increased $95 \%$ and $124 \%$, respectively. The PU + GNP nanocomposite displayed the highest tearing strength and the PU + GNP + SG nanocomposite showed the highest elongation at break. An investigation of the microstructures of the modified PUs by FTIR, field emission scanning electron microscope (FESEM) and energy-dispersive X-ray spectroscopy (EDX) are discussed. Hydrophobicity of the PU and developed PU nanocomposites are reported by measuring their water droplet contact angles and their free surface energies.
\end{abstract}

\section{Keywords}

Graphene, sol-gel, silica, polyurethane, erosion resistance, wind turbine blade

Received I October 2021; accepted 29 December 202I

\section{Introduction}

Leading edge erosion (LEE) of wind turbine blades caused by the impact of rain, dust, salty vapour, hailstones, and insects, reduces the lifetime of the blades. This in turn results in a loss in annual energy production (AEP) by the turbines. Potential AEP losses of between 4.5 and $25 \%$ have been reported by Sareen, ${ }^{1}$ and losses from $2 \%$ to $3.7 \%$, depending on the extent of damage at the leading edge, have been reported by Han et al. ${ }^{2}$ Sandia National Laboratories ${ }^{3}$ estimated the AEP losses as $5-$ $8 \%$. Kruse et al. ${ }^{4}$ simulated the aerodynamic performance of a NACA $63_{3}-418$ and reported up to $35 \%$ reduction in lift and $90 \%$ reduction in glide ratio for the specified angle of attacks ranges. Hence, there are major incentives for protecting the leading edge of wind turbine blades.

Elastomeric materials are currently considered to be amongst the best candidates for LEE protection ${ }^{5,6,7,8}$ and polyurethanes are one of the best choices. Polyurethane (PU) elastomers have a urethane group -NH-CO-O in their structure. PUs are formed by the reaction of isocyanates $\left(\mathrm{R}-(N=\mathrm{C}=\mathrm{O})^{\mathrm{n}}\right.$ ] with polyols. Control of segmentation through stoichiometry and

'Department of Mechanical Engineering, Kingston University, London, UK

${ }^{2}$ Department of Wind Energy, Technical University of Denmark, Roskilde, Denmark

${ }^{3}$ Center for Membranes and Advanced Water Technology (CMAT), Department of Chemical Engineering, Khalifa University of Science and Technology, Abu Dhabi, UAE

${ }^{4}$ Thermal Spray Center (CPT), Universitat de Barcelona, Barcelona, Spain

Corresponding author:

Homayoun Hadavinia, Department of Mechanical Engineering, Kingston University London, Roehampton Vale, Friars Avenue, London, SWI5 3DW, UK. Email: h.hadavinia@kingston.ac.uk

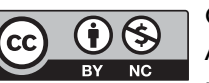


reaction conditions allows the creation of PU elastomers with superior qualities. ${ }^{9,10}$ In addition, PUs have a high capacity for energy absorption, making them particularly suitable for shock and impact protection. Thus, PUs are good candidates for leading edge protection. In PU, the hard domains are embedded in a rubbery soft segmented matrix. Depending on the hard segment content, the morphology of the hard domains changes from one of isolated domains to one of interconnected domains. At room temperature, soft domains are above their glass transition temperature and responsible for rubber-like behaviour while hard domains are below their glassy or melting transition temperature. The latter are the primary contributors to the hysteresis, permanent deformation, high modulus and tensile strength of the materials. ${ }^{11}$ A wide range of mechanical properties can be obtained in PUs by varying the molecular weight and the ratio and chemical composition of the hard and soft segments.

When a rain drop hits the surface coating, it generates three different types of waves: shear, compression and Rayleigh. ${ }^{12}$ The shear wave is the cause of surface coating tearing; this failure has two phases, first is a period in which cracks nucleate in the regions that were initially free from observable cracks, followed by a second phase in which cracks grow to the point of failure. For this reason, developing a coating material with high tear resistance is desirable for highly durable rain erosion coatings.

It is evident that the mechanical, thermal and impact properties of polymers can be significantly improved by the addition of nanoparticles. ${ }^{13}$ Nanoparticles tend to intercalate and exfoliate in a polymer under appropriate conditions, increasing substantially the area of interface with the polymer. ${ }^{13}$ The strength of the interface and the dispersion of nanoparticles are central to the mechanical enhancement of nanoparticle modified polymers. ${ }^{14,15}$ The strength of interface can be improved by functionalisation of nanoparticles to facilitate chemical bonding with the matrix. Surface functional groups such as hydroxyl, carboxyl, or amine groups on the nanofillers can potentially form chemical bonds with the polymer matrices, resulting in stronger interfaces between the fillers and the matrix. In addition, the nanoparticles (in this case graphene) and polymeric matrices interact by mechanical interlocking through the wrinkled surface of thin graphene sheets. As an example, Chung et al. ${ }^{16}$ modified graphite (MG) powder with particle size $<20 \mu \mathrm{m}$ and covalently linked them to a PU backbone. The hydroxyl content $(-\mathrm{OH})$ of the $\mathrm{MG}$ is an important factor for linking graphite to the PU. The ultimate tensile stress increased $436 \%$, and the maximum strain increased by $1744 \%$ compared to unmodified PU.

In the past, several researchers have reported how the mechanical properties and erosion resistance of PU elastomers can be improved by addition of various nanoparticles. Malaki et al. ${ }^{17}$ reported a $29 \%$ improvement in the erosion resistance of PU coatings with the addition of $6 \mathrm{wt} \%$ of fumed nanosilica. Petrovic et al. ${ }^{18}$ made PU nanocomposite with nanosilica filler concentration ranging from 0 to $50 \mathrm{wt} \%$. They showed the coefficient of thermal expansion decreased with increasing nanosilica content. At $40 \mathrm{wt} \%$ nanosilica concentration, the tensile strength was increased 300\%. Elongation at break continuously increased with increasing nanosilica content, reaching an increase of $600 \%$ at $50 \mathrm{wt} \%$. Chung et al. ${ }^{19}$ prepared hybrid PU/silica composites using a sol-gel reaction between tetraethyl orthosilicate (TEOS) and triethoxysilyl groups (TESPI) grafted onto PU. The ultimate tensile strength (UTS) sharply increased from the cross-linking of the grafted silica at low TEOS concentrations but decreased with the increase in TEOS content as the excess silica inhibited cross-linking: The UTS of PU without TEOS and TESPI (15.2 MPa) increased to 59.6 MPa at $12.5 \mathrm{mmol}$ of TEOS and $2.5 \mathrm{mmol}$ of TESPI ( $290 \%$ increase). Syamsundar et al. ${ }^{20}$ studied erosion wear resistance of PU coatings modified with boron carbide $\left(\mathrm{B}_{4} \mathrm{C}\right)$ or silicon carbide ( $\mathrm{SiC}$ ) nanoparticles. They found the optimum nanoparticle loading with $\mathrm{B}_{4} \mathrm{C}$ was $20 \mathrm{wt} \%$ and $10 \mathrm{wt} \%$ for $\mathrm{SiC}$, beyond these loadings the performance deteriorated. Mills et al. ${ }^{21}$ modified PU coatings with 5 and $10 \mathrm{wt} \%$ of nanosilica and found that with a $5 \mathrm{wt} \%$ loading, ionic resistance was significantly increased due to the polymer network reinforcement and water absorption was reduced. Kotnarowska et al. ${ }^{22}$ reported that the type of nanofiller and its size significantly affected the erosion resistance of PU coatings. The greatest erosion resistance was obtained for PU modified with silica having the smallest filler grain. Pokharel et al. ${ }^{23}$ manufactured PU nanocomposites by in-situ polymerisation using pristine graphene nanoplatelets (GNPs), graphene oxide (GO) and functionalized graphene sheets (FGSs). The PU nanocomposites with a $2 \mathrm{wt} \%$ loading of GO or FGS showed significantly higher Young's modulus than the one modified with GNPs. Tarasov et al. ${ }^{24}$ analysed the effect of fullerene, GO and their mixture (15/85 ratio) on cross-linked PU urea elastomer for filler loading of $0.01 \mathrm{wt} \%$ to 0.1 $\mathrm{wt} \%$. Addition of fullerene resulted in a $10 \%$ decrease in Young's modulus at $0.1 \mathrm{wt} \%$ filler loading, while GO increased Young's modulus by $10 \%$ relative to the neat PU. The use of fullerene/GO additive demonstrated a pronounced positive synergetic effect and resulted in a $20 \%$ increase in Young's modulus for $0.01 \mathrm{wt} \%$ loading and a $30 \%$ increase at $0.1 \mathrm{wt} \%$ loading; however, a weak negative synergetic effect on tensile strength was observed. Xia and Song ${ }^{25}$ studied PU-carbon nanotubes (single- and multi-walled) composites prepared by in-situ polymerisation with $0.5,1$ and 2 wt $\%$ CNT. The highest tensile strength of $9.11 \mathrm{MPa}$ was achieved at $2 \mathrm{wt} \%$ loading of single-walled CNT. Tayfun et al. ${ }^{26}$ prepared $0.5,1,1.5 \mathrm{and} 2 \mathrm{wt}$ $\%$ CNT reinforced thermoplastic polyurethane (TPU) composites by melt-mixing. The highest improvement of $41 \%$ in UTS was obtained for $0.5 \mathrm{wt} \%$ nitric acid-treated CNT and the highest increase of $150 \%$ in Young's modulus was achieved at $1 \mathrm{wt} \%$ of CNT loading. Guo et al. ${ }^{27}$ used multi-walled CNTs (MWCNTs) for reinforcement of PU by the combination of in-situ polymerisation and solution-casting approach. Incorporation of $1.0 \mathrm{wt} \%$ loading of MWCNTs into a PU matrix significantly improved Young's modulus, stress-at-break and the elongation at break by $90 \%, 500 \%$, and $75 \%$, respectively. Kumar et al. ${ }^{28}$ synthesised PU with 1-10 wt \% MWCNTs in a two-step solution mixing and compression moulding process for producing PU thin films. The results of quasi-static nanoindentation tests showed elastic modulus and hardness were continuously improved by increasing the MWCNT loading; they increased $124 \%$ and $53 \%$, respectively, for $10 \mathrm{wt} \%$ MWCNT loading and the fracture resistance improved by $52 \%$ for $7 \mathrm{wt} \%$ MWCNTs loading. Li et al. ${ }^{29}$ used various loadings of acid-treated MWCNTs for reinforcement of polyisobutylene (PIB)/polyethylene glycol (PEG)-based polyurethane nanocomposites (PIGNTs). A $126 \%$ improvement of UTS was achieved at low loading of $0.3 \mathrm{wt} \%$ MWCNT. Additionally, the PIB/PEG-based PU and PIGNTs exhibit excellent damping properties $(\tan \delta>0.3)$ in a wide range of temperature from $-60^{\circ} \mathrm{C}$ to $35^{\circ} \mathrm{C}$. Eivazi Zadeh 
et al. ${ }^{30}$ prepared PPU/CNT composites containing $0.05 \%, 0.1 \%, 0.5 \%$, and $1 \% \mathrm{wt} \%$ CNTs by electrospinning. The highest increase in toughness ( 4.5 times) and stiffness (3.5 times) was achieved with $0.5 \mathrm{wt} \% \mathrm{CNT}$. In addition, although the existence of CNTs did not affect the contact angle significantly, it increased the hydrophilicity of PU to a maximum at $0.1 \mathrm{wt} \% \mathrm{CNTs}$ loading. Moghim et al. ${ }^{31}$ studied TPU reinforced with $0.05-5 \mathrm{wt} \%$ loading of MWCNT, prepared using a solution-casting method. Tensile strength of PU was enhanced about $122 \%$ with $1 \mathrm{wt} \%$ CNTs loading. Alberto et al. ${ }^{32}$ tested PU resin films reinforced with few-layered graphene (FLG) nanoparticles and observed an improvement of over 100\% in the abrasion resistance, a $25 \%$ increase in the coefficient of static friction and a $200 \%$ increase in the coefficient of dynamic friction. Qiao et al. ${ }^{33}$ developed hydrophobic polydimethylsiloxane-based PUs (Si-PUx) with hydroxypropyl polydimethylsiloxane (H-PDMS). They showed that the cavitation erosion resistance of Si-PUx coatings improved with an increase in the H-PDMS content. The cumulative mass loss of Si-PUx with $12.5 \mathrm{wt} \% \mathrm{H}-\mathrm{PDMS}$ was $2.96 \mathrm{mg}$ without any visible holes and cracks on the surface after $80 \mathrm{~h}$ testing. Rihayat et al. ${ }^{34}$ used a polyether polyol in the production of a PU by reaction with an isocyanate. The clay was treated with cetyltrimethyl ammonium bromide (CTAB) and octadodecylamine (ODA) and the resulting organoclay was intercalated in the PU. The largest increase of $166 \%$ in tensile strength and $600 \%$ in elongation at break achieved with $5 \mathrm{wt} \%$ loading of ODA modified clay.

In our previous work, ${ }^{35}$ erosion tests with rubber ball impact have been conducted on specimens made from glass fibre reinforced polymer (GFRP) composite substrates coated with neat PU, PU + GNP and PU + GNP + SG materials. The results showed PU coatings modified with $0.5 \mathrm{wt} \%$ GNP and $1 \mathrm{wt} \%$ SG had up to 13 times longer life than unmodified PU ${ }^{35}$ In the work reported here, the optimised processing stages of making these PU nanocomposites are discussed. The enhancement in the mechanical properties and energy absorption capacity of the PU nanocomposite coatings are explored by tensile, monotonic and cyclic compression, and tearing tests. The characterisation of modified PUs by FTIR, field emission scanning electron microscope (FESEM), and energy-dispersive X-ray spectroscopy (EDX) together with the results of water droplet contact angle and the free surface energy of the developed PU nanocomposites are presented.

\section{Materials and methods}

\section{Materials}

The two components PU system BAYTEC ${ }^{\circledR} 9005$ 60A MF polyol with viscosity of 800-1600 mPa.s and specific gravity of 1.01-1.04 and the DESMODUR ${ }^{\circledR}$ B9 M10 polyisocyanates crosslinkers with viscosity of 120-200 mPa.s and specific gravity of 1.21-1.23 were supplied by Covestro. PUs were produced by reacting polyisocyanates with polyols at room temperature with the mixing ratio by weight of polyol to polyisocyanates of 100:37.

The as-received functionalised graphene nanoplatelets HDPlas ${ }^{\mathrm{TM}} \mathrm{f}-\mathrm{GNP}$, containing surface carboxyl groups created by a 'split plasma' treatment in oxygen were supplied by Haydale Ltd, UK. The plasma functionalisation is a low temperature, low energy, dry process, with no effluent disposal, and is benign to the structure of the raw material. The functional groups are only attached to the edges, dislocation sites and defects. The lateral dimension of the f-GNP (hereafter, it is called GNP for brevity) is between 0.3 and $5 \mu \mathrm{m}$ with typical individual GNP thickness of about $0.34-0.5 \mathrm{~nm}$, bulk density of $215 \mathrm{~kg} / \mathrm{m}^{3}$ and specific surface area of $\sim 25 \mathrm{~m}^{2} / \mathrm{g}$. The graphene sheets have an aspect ratio of $\sim 85$.

Hydrophobic silica-based sol-gel P029 ${ }^{\mathrm{TM}}$ was supplied by Sol-Gel Materials \& Applications (SGAM), Gillingham, UK, and it contains $15 \mathrm{wt} \% \mathrm{Si}$.

PU and its nanomodified nanocomposites are used in this work to make the LE protection coating. The three coating materials are neat PU, graphene modified PU (PU + GNP) and graphene + sol-gel modified PU $(\mathrm{PU}+\mathrm{GNP}+\mathrm{SG})$.

\section{Preparation of polyurethane material}

BAYTEC $^{\circledR} 9005$ 60A MF polyol was mixed with DESMODUR ${ }^{\circledR}$ B9 M10 polyisocyanates with mass ratio of 100:37 at room temperature $\left(25^{\circ} \mathrm{C}\right)$ for 3 min using a homogeniser at $8000 \mathrm{rpm}$. The mixture was then placed into a degassing chamber for 5 min, and after that, it was used for moulding various test coupons.

\section{Preparation of PU + GNP material}

$\mathrm{PU}+$ GNP composites were prepared by in-situ polymerisation approaches. The in-situ polymerisation of PU + GNPs was carried out by directly mixing GNP $(0.5 \mathrm{wt} \%)$ with polyol at room temperature $\left(25^{\circ} \mathrm{C}\right)$ using a homogeniser. The GNP and PU mixing procedure was optimised at three different speeds and duration time. It was found that mixing at $8000 \mathrm{rpm}$ for $18 \mathrm{~min}$ gave the most homogenous mixture with little damage to the structure of graphene nanoparticles. Subsequently DESMODUR ${ }^{\circledR}$ B9 M10 polyisocyanates was added to the mixture and stirred for $1 \mathrm{~min}$. The functionalised graphenes act as chemical crosslinkers in PUs. The mixture was ready for moulding various test coupons.

\section{Preparation of PU + GNP + SG material}

The in-situ polymerisation of PU + GNP + SG was carried out by directly mixing hydrophobic silica-based solution SG (1 wt $\%$ ) with the DESMODUR ${ }^{\circledR}$ B9 M10 polyisocyanates and then the mixture was added to a mixture of polyol + GNP (same 
preparation method as above), stirred for 1 min using a homogeniser at $8000 \mathrm{rpm}$ before being used for moulding various test coupons.

\section{Testing methods}

Tensile tests. Tensile tests were carried out at room and elevated temperatures with different strain rates. A mould for casting uniaxial tensile test coupons was manufactured from aluminium. The dogbone specimen dimensions accord to BS EN ISO 527-2:2012 (Type 1BA geometry) for elastomers, Figure 1(a). After the degassing process, the PU mixtures were gently poured into the mould and left until polymerisation was completed at room temperature. The tests were carried out $24 \mathrm{~h}$ after casting the specimens.

The tensile tests were carried out using a Zwick/Roell universal testing machine fitted with a $50 \mathrm{kN}$ load cell. The crosshead speed was set at 21, 105 and $210 \mathrm{~mm} / \mathrm{min}$ (equivalent to strain rate of $0.01,0.05$ and $0.1 \mathrm{~s}^{-1}$ ) and at each strain rate, tensile tests were performed at three different temperatures $25(\mathrm{RT}), 50$ and $70^{\circ} \mathrm{C}$ using an in-situ heating chamber. For each case, six specimens were tested. Young's modulus (E), ultimate tensile strength (UTS), elongation at break EL (\%) and modulus of toughness $(\mathrm{T})$ were evaluated at each temperature and strain rate.

Compression tests. For these tests, cylindrical samples with a diameter of $12 \mathrm{~mm}$ and thickness of $3 \mathrm{~mm}$ were manufactured. First, a sheet of material, $3 \mathrm{~mm}$ in thickness, was manufactured by casting the PU or modified PU into a machined aluminium mould. The PU sheet was removed from the mould and then a die cutter with a hydraulic press machine was used to cut the specimens with the required shape and dimensions.

The compression tests were carried out using Zwick/Roell universal testing machine fitted with a $50 \mathrm{kN}$ load cell. An extensometer was used to record the compression of the specimens. The extensometer was connected to the machine with a specially designed fixture. In the compression tests, the crosshead speed was set at 21,105 and $210 \mathrm{~mm} / \mathrm{min}$ (equivalent to strain rate of $0.01,0.05$ and $0.1 \mathrm{~s}^{-1}$ ) and at each strain rate, the tests were performed at three different temperatures $25^{\circ} \mathrm{C}(\mathrm{RT})$, $50^{\circ} \mathrm{C}$ and $70^{\circ} \mathrm{C}$ using an in-situ heating chamber during compression. For each case, three specimens were tested.

Tearing tests. Angle tear strength test specimens with a nick were made according to the ISO 34-1:2015 tearing test standard. ${ }^{36}$ The tests were performed at standard laboratory temperature $\left(23{ }^{\circ} \mathrm{C} \pm 2{ }^{\circ} \mathrm{C}\right)$ to measure the force required to propagate a prenick cracked specimen. Tearing tests were performed with a Zwick/Roell universal testing machine fitted with a $50 \mathrm{kN}$ load cell. The tests were operated without interruption at a constant rate of travel until the test piece breaks. The crosshead speed was kept at $500 \mathrm{~mm} / \mathrm{min} \pm 50 \mathrm{~mm} / \mathrm{min}$ and the applied forces and crosshead movement were recorded during the test. For each type of material, three specimens were tested.

The measured tear strength indicates the resistance to the propagation of a defect, such as a nick in the specimen. In the angle tear test, the force required to tear a specified test piece along the nick already made in the test piece is measured. For calculating the tearing strength $\left(T_{S}\right)$, the maximum force required to extend the nick cut during tearing is divided by the thickness of the specimen $(d)$

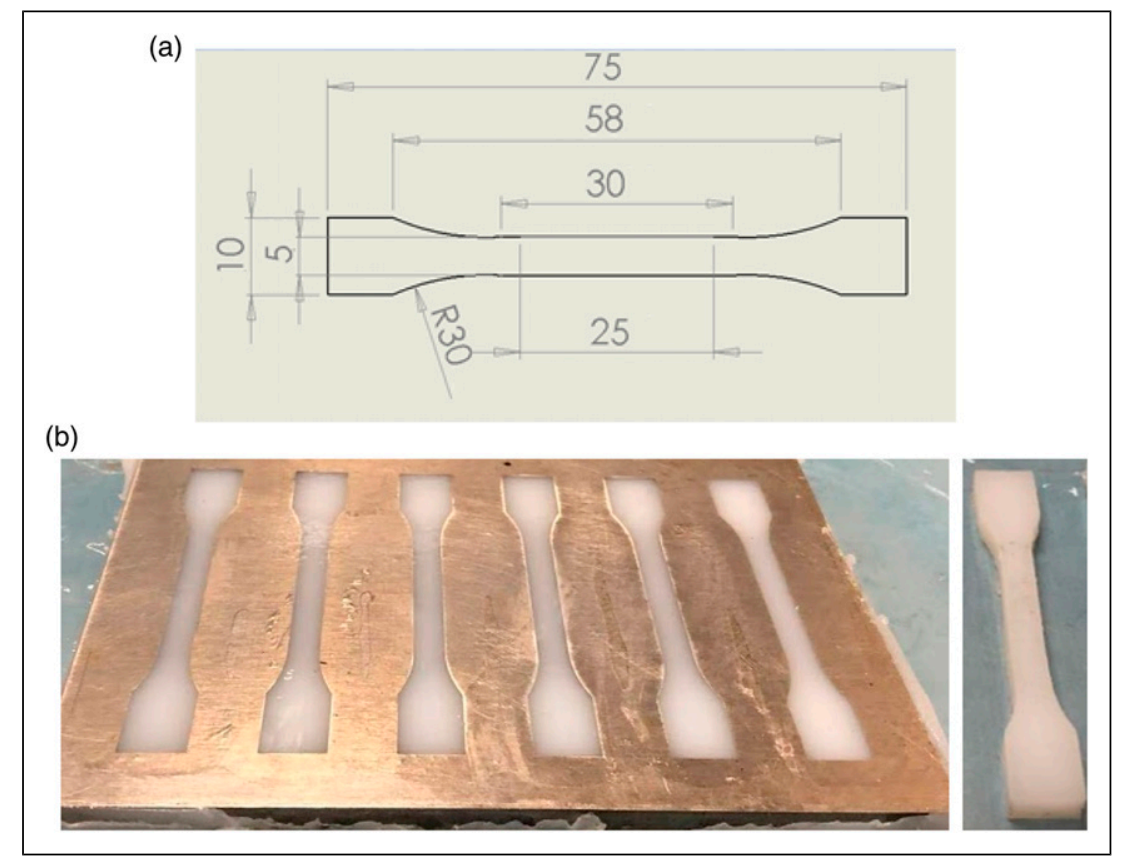

Figure I. (a) Dimensions of dogbone specimen based on BS EN ISO 527-2:20I2 (Type IBA geometry) and (b) casting of neat PU specimens for tensile testing. 


$$
T_{s}=\frac{F_{\max }}{d}\left(\frac{k N}{m}\right)
$$

The tearing test specimens were made by the moulding method. A suitable mould was made by the CNC machining of resin tooling boards (Figure 2). After removing the specimens from the mould, a sharp razor blade was used to cut a sharp nick at the point of stress concentration in the tear test specimens according to the ISO 34-1:2015 standard. The razor blade (cutting tool) was clamped in a plane perpendicular to the surface of the specimen and no lateral movement was permitted during introduction of the nick into the specimens. ${ }^{36}$ The blade was wetted with soap solution prior to nicking. The depth of the nick was $1 \mathrm{~mm} \pm 0.2 \mathrm{~mm}$ at the apex of the internal angle of the test specimen. The tearing force and crosshead displacement were recorded during crack propagation. Three specimens were tested for each material.

Scanning electron microscopy and infrared spectroscopy. The PU and the modified PU nanocomposites surface morphology was examined using field emission scanning electron microscopy (FESEM), with Quanta-FEG-250 model. All samples were cleaned with pressurised air followed by ethanol washing to remove any adsorbed particles. The samples were coated with 10 $15 \mathrm{~nm}$ of platinum to inhibit charging and improve the secondary electron signal, allowing for better imaging of the samples. All FESEM samples were mounted on SEM stubs using carbon tape with adhesive sides and the images were taken at 75 to 5000 magnification at $5 \mathrm{kV}$. Energy-dispersive X-ray spectrometrt (EDX) with acceleration voltage (10-15 kV) was used to study the elemental composition of neat PU and their nanocomposites.

Fourier-transform infrared (FTIR) spectra were obtained using a PerkinElmer Spectrum Two spectrometer and the data were analysed with PerkinElmer Spectrum Version 10.03.09 software.

Contact angle and surface energy measurement. The static deionised (DI) water contact angles (CA) for PU, PU + GNP and $\mathrm{PU}+\mathrm{GNP}+\mathrm{SG}$ coatings were measured for $6000 \mathrm{~ms}$ after application of the water droplet (Sessile drop method) with a Krüss $\mathrm{GmbH} /$ Drop Shape Analyzer (DSA) machine using $5 \mu \mathrm{L}$ DI water droplets ejected from a micro-syringe in order to study the changes in the surface water amphiphobicity.

The surface free energy $(-\Delta \mathrm{GSL})$ was calculated using the Young-Dupre equation ${ }^{37}$ equation (2)

$$
-\Delta G_{S L}=(1+\cos \theta) \gamma_{L}^{T}
$$

where $\gamma_{L}^{T}$ is the water surface tension $\left(72.8 \mathrm{~mJ} \cdot \mathrm{m}^{-2}\right)$ and $\theta$ is the measured DI water contact angle.

\section{Results and discussion}

\section{Tensile tests results}

The tensile properties of the neat $\mathrm{PU}$ and its modified nanocomposites were investigated at different temperatures: $25^{\circ} \mathrm{C}(\mathrm{RT})$, $50^{\circ} \mathrm{C}$ and $75^{\circ} \mathrm{C}$ and at different strain rate: $0.01 \mathrm{~s}^{-1}, 0.05 \mathrm{~s}^{-1}$ and $1 \mathrm{~s}^{-1}$.

Tensile properties of the neat PU. A sample of true stress-strain diagram of neat PU at strain rate of $0.01 \mathrm{~s}^{-1}$ and temperatures of $25^{\circ} \mathrm{C}, 50^{\circ} \mathrm{C}$ and $70^{\circ} \mathrm{C}$ is shown in Figure 3. Young's modulus, elongation at break, UTS and modulus of toughness were extracted from true strain-stress diagrams and the results are summarised in Table 1.

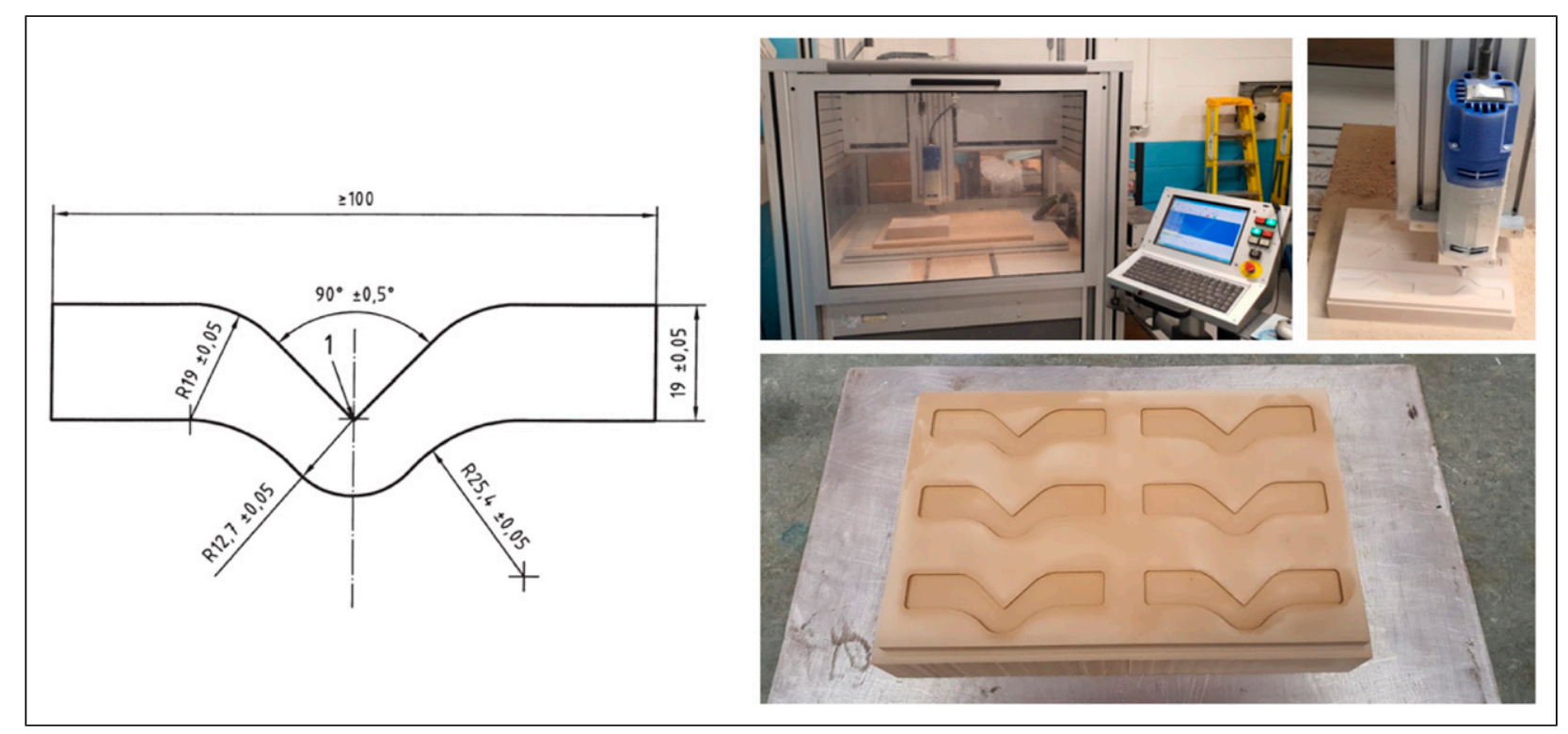

Figure 2. Process of mould manufacturing for preparation of tearing test specimens by CNC machining of resin tooling board. 
The results show that by increasing the strain rate, Young's modulus increased for all three temperatures. At $25^{\circ} \mathrm{C}(\mathrm{RT})$, by increasing the strain rate from $0.01 \mathrm{~s}^{-1}$ to $0.05 \mathrm{~s}^{-1}$, initial Young's modulus increased $14.7 \%$, but no further increase was seen by increasing the strain rate to $0.1 \mathrm{~s}^{-1}$.

The elongation at break values increased with increasing the strain rate for all three temperatures. However, at the same strain rate, increasing the temperature decreases elongation at break. For example, at the strain rate of $0.01 \mathrm{~s}^{-1}$, by increasing the temperature from $25^{\circ} \mathrm{C}$ to $70^{\circ} \mathrm{C}$, the elongation at break decreased by $308 \%$ and at the strain rates of $0.05 \mathrm{~s}^{-1}$ and $0.1 \mathrm{~s}^{-1}$, EL decreased by $118 \%$ and $134 \%$, respectively.

As expected, the UTS increased by increasing the strain rate, for example, by increasing the strain rate from $0.01 \mathrm{~s}^{-1}$ to $0.1 \mathrm{~s}^{-1}$ at $70^{\circ} \mathrm{C}$, the UTS increased by $52 \%$, it increased $20 \%$ at $50^{\circ} \mathrm{C}$ and $226 \%$ at $70^{\circ} \mathrm{C}$. However, at the same strain rate, the UTS decreased with increasing temperature.

The modulus of toughness is calculated by measuring the area under the true strain-stress curve. Generally, the modulus of toughness increased with increasing strain rate for all temperatures; the largest increase occurred at room temperature. At a constant strain rate, the modulus of toughness decreased with increasing temperature. The maximum modulus of toughness $13,302 \mathrm{~kJ} / \mathrm{m}^{3}$ was observed at room temperature and a strain rate of $0.1 \mathrm{~s}^{-1}$ and the lowest value of $1255 \mathrm{~kJ} / \mathrm{m}^{3}$ were seen at strain rate of $0.01 \mathrm{~s}^{-1}$ at $70^{\circ} \mathrm{C}$.

Tensile properties of the PU + GNP. The PU was modified with $0.1,0.2,0.3,0.5$ and $1 \mathrm{wt} \%$ loading of GNP. Tensile tests were carried out at room temperature $\left(25^{\circ} \mathrm{C}\right)$ and $0.05 \mathrm{~s}^{-1}$ strain rate to determine the optimum loading of the graphene. The engineering strain $\left(\varepsilon_{e}\right)$-engineering stress $\left(\sigma_{e}\right)$ results for different GNP loading are shown in Figure 4 . The PU + GNP nanocomposite with GNP loading of $0.5 \mathrm{wt} \%$ displayed the best performance.

True strain $\left(\varepsilon_{t}\right)$ and true stress $\left(\sigma_{t}\right)$ values were calculated by assuming constant volume from the following equations

$$
\begin{gathered}
\varepsilon_{t}=\ln \left(1+\varepsilon_{e}\right) \\
\sigma_{t}=\sigma_{e}\left(1+\varepsilon_{e}\right)
\end{gathered}
$$

Young's modulus, EL\%, UTS and modulus of toughness data for PU modified with different GNP loading are extracted from true strain-true stress diagrams and they are summarised in Table 2. The results show the largest Young's modulus, UTS and modulus of toughness value relative to neat PU were achieved for PU with $0.5 \mathrm{wt} \%$ GNP loading. At $0.5 \mathrm{wt} \%$ loading, the UTS increased by $76 \%$ and UTS and modulus of toughness increased by $76 \%$ and $91.6 \%$ relative to neat PU, respectively. The drop of Young's modulus, UTS, and the modulus of toughness values at higher GNP loading of $1 \mathrm{wt} \%$ relative to $0.5 \mathrm{wt} \%$ loading is probably due to agglomeration of GNP nanoparticles.

Tensile properties of the PU + GNP + SG. In order to investigate the impact on the mechanical properties of PU materials by adding hydrophobic silica, the following samples were prepared and tested at room temperature.

Figure 5(a) shows the variation in Young's modulus for neat PU and various PU nanocomposites. Highest Young's modulus was obtained from the PU modified with $1 \mathrm{wt} \% \mathrm{SG}$ and the next highest was for the PU modified with $0.5 \mathrm{wt} \%$ GNP $+1 \mathrm{wt} \%$ SG. Increasing the loading of SG from $1 \%$ to $2.5 \%$ adversely affected Young's modulus of PU + GNP + G nanocomposite.

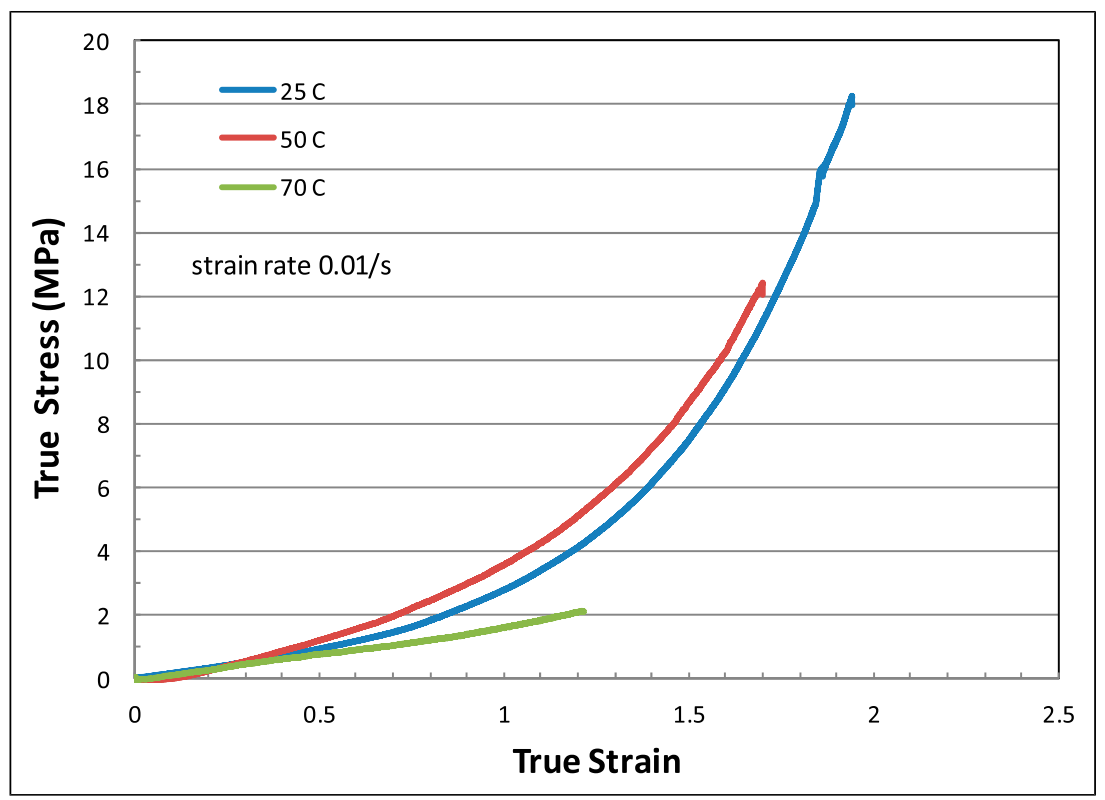

Figure 3. True stress-strain diagram of neat $\mathrm{PU}$ at strain rate of $0.01 \mathrm{~s}^{-1}$ and temperatures of $25^{\circ} \mathrm{C}, 50^{\circ} \mathrm{C}$ and $70^{\circ} \mathrm{C}$. 


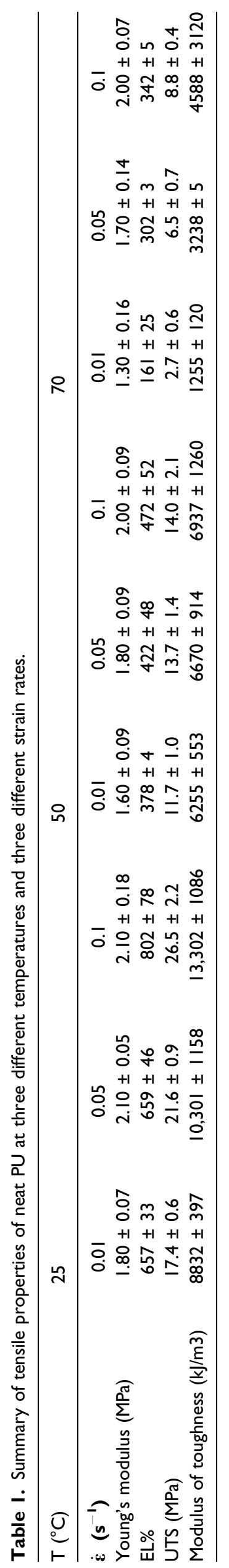


The effect of sol-gel loading on the elongation at break of neat PU and modified PU + GNP is shown in Figure 5(b). Adding SG to the neat PU decreases the elongation at break substantially; however, for PU + GNP, the reduction is small. The greatest elongation at break value is obtained for neat PU and the lowest one is for the PU $+0.5 \mathrm{wt} \% \mathrm{GNP}+2.5 \mathrm{wt} \% \mathrm{SG}$.

The effect of SG loading on the UTS of neat PU and modified PU + GNP is shown in Figure 5(c). A $1 \mathrm{wt} \% \mathrm{SG}$ loading to the neat PU and modified PU + GNP, resulted in an increase in the UTS; but further increasing the SG loading to $2.5 \mathrm{wt} \%$ resulted in a decrease in the UTS value for both neat PU and PU + GNP.

The effect of SG loading on the modulus of toughness is shown in Figure 5(d). At $1 \mathrm{wt} \% \mathrm{SG}$ loading, the modulus of toughness increased for both the neat PU and the PU + GNP nanocomposite. However, at a higher SG loading of $2.5 \mathrm{wt} \%$, the modulus of toughness decreased for neat PU and PU + GNP.

In summary, tensile tests of PU and modified PUs showed that the best performance is achieved with PU $+0.5 \mathrm{wt} \% \mathrm{GNP}+$ $1 \mathrm{wt} \%$ SG nanocomposite. Young's modulus, UTS, elongation at break and modulus of toughness for neat PU and modified PUs are summarised in Table 3.

\section{Compression tests of neat PU, PU + GNP and PU + GNP + SG}

Monotonic compression tests were performed on neat PU, PU + GNP and PU + GNP + SG nanocomposites at room temperature and 25,50 and $75^{\circ} \mathrm{C}$ for three different strain rates.

Uniaxial compression tests result for PU at $25^{\circ} \mathrm{C}$ and for three strain rates are shown in Figure 6(a). The results indicate that neat PU has minimal strain rate dependency at room temperature, and the mechanical properties are only slightly affected by changing the strain rate. However, at higher temperature, the compressive behaviour of neat PU was affected as shown in Figure 6(b).

Uniaxial compression test results for the $\mathrm{PU}+\mathrm{GNP}$ at $25^{\circ} \mathrm{C}$ and three strain rates are shown in Figure 6(c). The results indicate that neat PU has a slight strain rate dependency at room temperature. However, at higher temperature, the compressive behaviour of neat PU + GNP was substantially affected as shown in Figure 6(d).

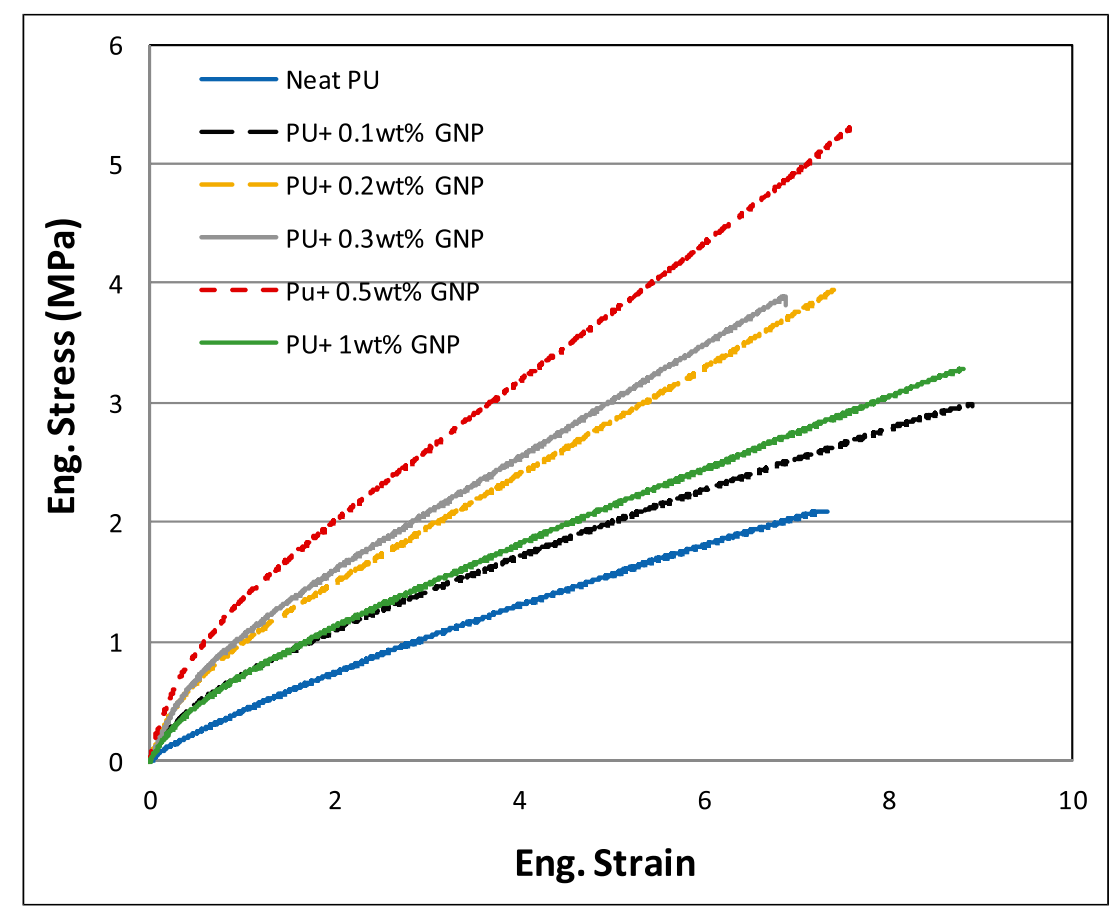

Figure 4. Engineering strain-stress of graphene modified PU at various GNP loading at RT and strain rate of $0.05 \mathrm{~s}^{-1}$.

Table 2. Tensile properties of PU and PU modified with $0.1,0.2,0.3,0.5$ and I wt\% loading of functionalised graphene (f-GNP) at room temperature $\left(25^{\circ} \mathrm{C}\right)$ and $0.05 \mathrm{~s}^{-1}$ strain rate.

\begin{tabular}{lcccccc}
\hline & \multicolumn{7}{c}{ PU + GNP at GNP loading wt\% } & & \\
\cline { 2 - 7 } & Neat PU & 0.1 & 0.2 & 0.3 & 0.5 & 1 \\
\hline Young's modulus (MPa) & $2.10 \pm 0.05$ & $1.90 \pm 0.05$ & $2.70 \pm 0.14$ & $2.90 \pm 0.02$ & $3.70 \pm 0.25$ & $2.10 \pm 0.04$ \\
EL\% & $659 \pm 66$ & $736 \pm 54$ & $651 \pm 33$ & $616 \pm 28$ & $599 \pm 36$ & $773 \pm 28$ \\
UTS (MPa) & $21.6 \pm 0.9$ & $26.0 \pm 2.7$ & $32.0 \pm 2.2$ & $35.0 \pm 3.3$ & $38.0 \pm 3.6$ & $31.0 \pm 2.0$ \\
Modulus of toughness $\left(\mathrm{kJ} / \mathrm{m}^{3}\right)$ & $10,301 \pm 1158$ & $13,979 \pm 1499$ & $16,244 \pm 927$ & $17,361 \pm 1590$ & $19,741 \pm 1832$ & $16,112 \pm 1015$ \\
\hline
\end{tabular}


Uniaxial compression test results for PU $+\mathrm{GNP}+\mathrm{SG}$ at $25^{\circ} \mathrm{C}$ and three strain rates are shown in Figure 6(e). The results indicate that similar to $\mathrm{PU}+\mathrm{GNP}$, $\mathrm{PU}+\mathrm{GNP}+\mathrm{SG}$ has a slight strain rate dependency at room temperature. However, the compressive behaviour of PU + GNP + SG is strongly affected by increasing the temperature as shown in Figure 6(f).

The effects of temperature and strain rate on the values of residual strain $\left(\varepsilon^{r}\right)$, compressive strength and energy absorption of neat PU, PU + GNP and PU + GNP + SG in monotonic compressive loading are extracted from Figure 6 are shown in Figure 7. At a fixed strain rate, an increase in the temperature caused a significant increase in the residual strain for PU. However, the effect of strain rate at the higher temperature of $70^{\circ} \mathrm{C}$ was less. The change in the compressive strength with increasing strain rate is small and it decreases with increasing temperature. Finally, energy absorption was calculated by measuring the area under the stress-strain curve in the compression test, and as shown in Figure 7(c) at higher temperature the energy absorption of neat PU decreases. For PU + GNP material, increasing the temperature at a fixed strain rate resulted in an increase in residual strain and decreases in the compressive strength and energy absorption. PU + GNP + SG material shows a similar pattern to those seen for PU + GNP material.

\section{Cyclic compression tests}

In this section, the result of true stress-true strain behaviour during cyclic compression loading-unloading tests for maximum strain $\varepsilon_{\max }=0.3$ and $\varepsilon_{\max }=0.5$ and at strain rate of $\dot{\varepsilon}=0.1 \mathrm{~s}^{-1}$ at $25^{\circ}$ are presented. Cyclic compression tests were performed up to five cycles $(N=5)$ for each sample.

The compressive true stress-true strain behaviour of neat PU with $\varepsilon_{\max }=0.5$ and $\dot{\varepsilon}=0.1 \mathrm{~s}^{-1}$ is shown in Figure 8(a) and for $\mathrm{PU}+\mathrm{GNP}$ with $\varepsilon_{\max }=0.5$ and $\dot{\varepsilon}=0.1 \mathrm{~s}^{-1}$ is shown in Figure 8(b) and for PU $+\mathrm{GNP}+\mathrm{SG}$ with $\varepsilon_{\max }=0.5$ and $\dot{\varepsilon}=0.1 \mathrm{~s}^{-1}$ is shown in Figure 8(c) and with $\varepsilon_{\max }=0.3$ and $\dot{\varepsilon}=0.1 \mathrm{~s}^{-1}$ is shown in Figure 8(d).

Residual strain at the end of cycles, compressive strength and energy absorption values for PU, PU + GNP and PU + GNP + SG are extracted from the cyclic stress-strain diagrams, and they are summarised in Table 4. The maximum compressive stress at maximum strain of 0.5 for $\mathrm{PU}$ is $107.9 \mathrm{MPa}$, for $\mathrm{PU}+\mathrm{GNP}$ it is $77.4 \mathrm{MPa}$ and for $\mathrm{PU}+\mathrm{GNP}+\mathrm{SG}$ it is $71.5 \mathrm{MPa}$.

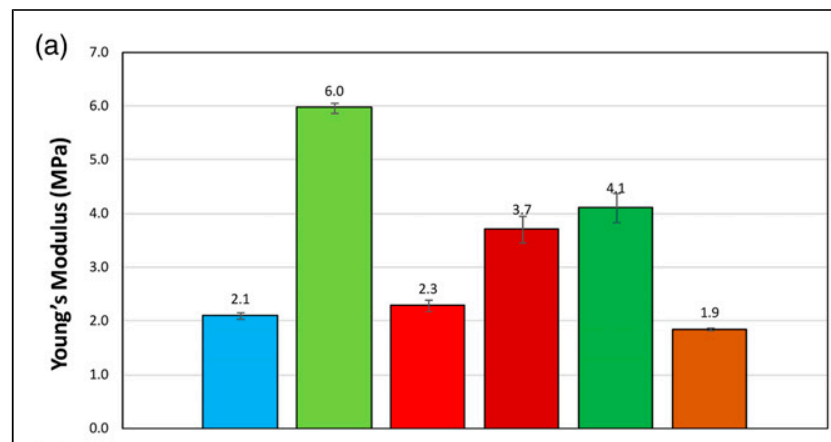

(c)

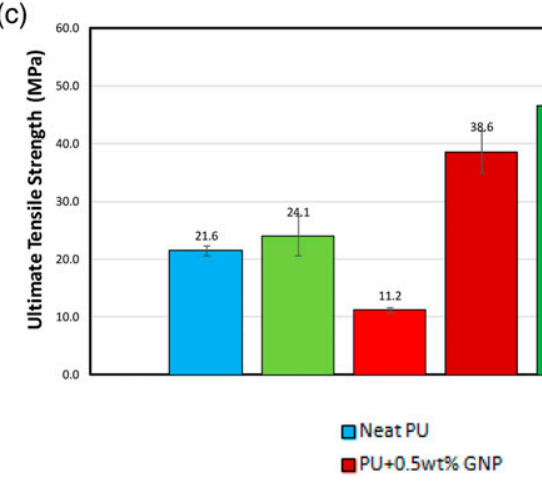

(b)

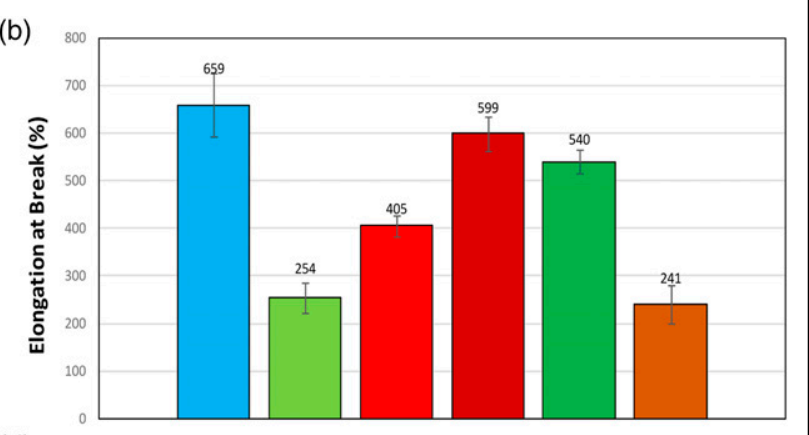

(d)

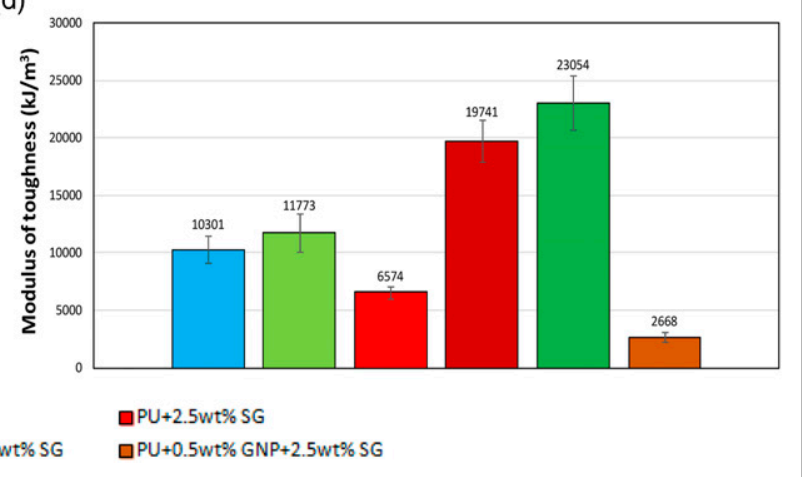

Figure 5. (a) Young's modulus, (b) elongation at break, (c) ultimate tensile strength and (d) modulus of toughness of neat PU, PU + SG and $\mathrm{PU}+\mathrm{GNP}+\mathrm{SG}$ at $25^{\circ} \mathrm{C}$.

Table 3. Tensile properties of the neat PU, 0.5 wt $\% \mathrm{f}-\mathrm{GNP}$ modified PU and 0.5 wt $\%$ GNP + I wt $\%$ SG modified PU at $25^{\circ} \mathrm{C}$.

\begin{tabular}{lccc}
\hline Properties & Neat PU & PU + GNP & PU + GNP + SG \\
\hline Young's modulus $(\mathrm{MPa})$ & $2.10 \pm 0.05$ & $3.7 \pm 0.3$ & $4.1 \pm 0.1$ \\
\%EL & $659 \pm 66$ & $599 \pm 36$ & $540 \pm 71$ \\
UTS $(\mathrm{MPa})$ & $21.6 \pm 0.9$ & $38.0 \pm 3.6$ & $46.5 \pm 11.5$ \\
Modulus of toughness $\left(\mathrm{kJ} / \mathrm{m}^{3}\right)$ & $10301 \pm 1158$ & $19741 \pm 1832$ & $23054 \pm 2376$ \\
\hline
\end{tabular}




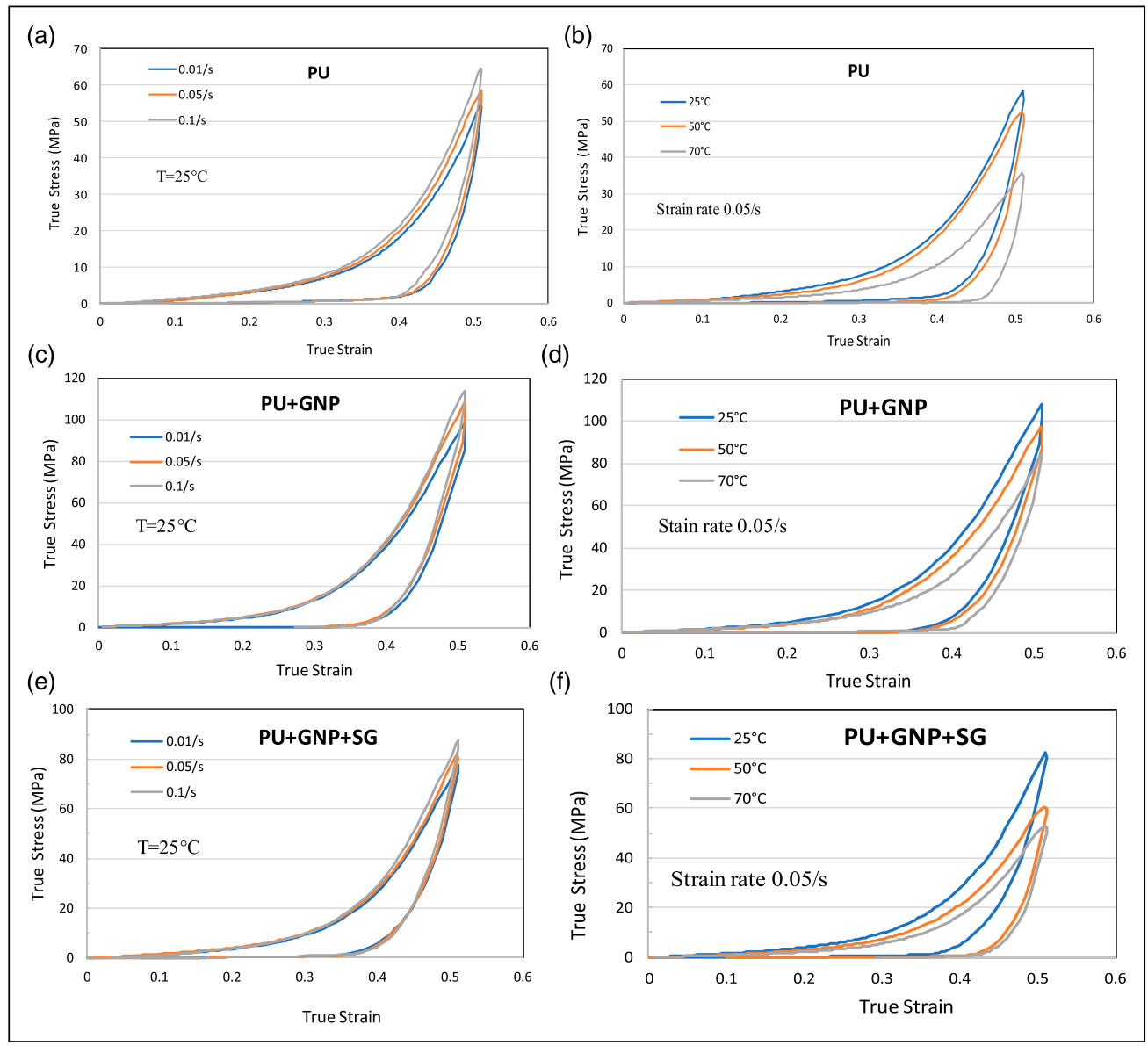

Figure 6. True strain-stress at strain rate of $0.01,0.05$ and $0.01 \mathrm{~s}^{-1}$ at temperature of $25^{\circ} \mathrm{C}$, and at strain rate of $0.05 \mathrm{~s}^{-1}$ at $25^{\circ} \mathrm{C}, 50^{\circ} \mathrm{C}$ and $70^{\circ} \mathrm{C}$ for $(\mathrm{a}, \mathrm{b})$ neat PU, (c, d) PU + GNP and (e, f) PU + GNP + SG, respectively.

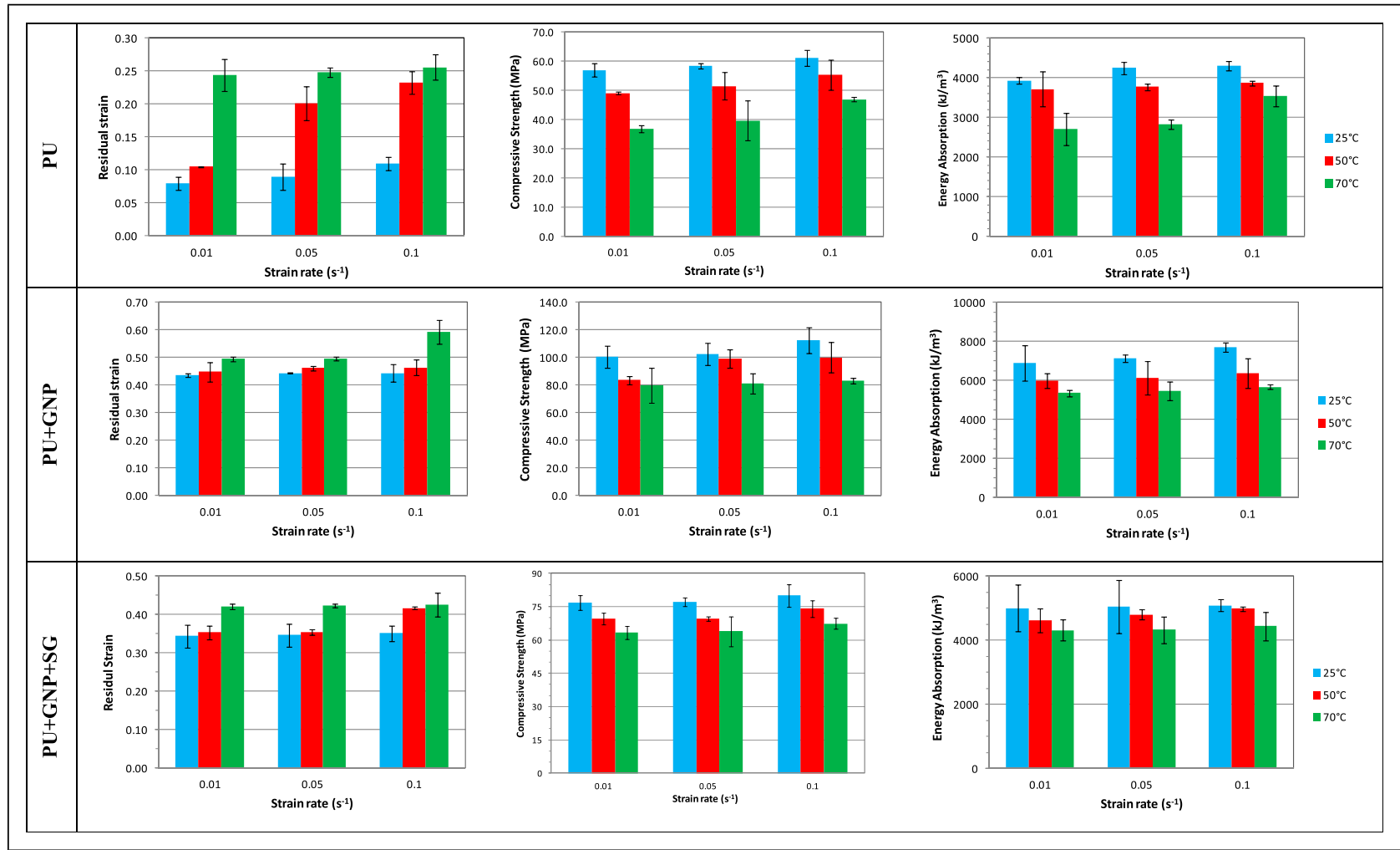

Figure 7. Residual strain, compressive strength and energy absorption of the neat PU (top row), PU + GNP (middle row) and PU + GNP + SG (bottom row) versus strain rate at three different temperatures. 
The compressive cyclic loading tests show that the stress-strain curve in the second cycle is far more compliant than that observed in the first cycle, which explains the softening behaviour of all three coating materials after cyclic loading. In addition, the stress-strain behaviours for all three coatings are stabilised after the first cycle. At a maximum strain of 0.5 , the stress magnitude reaches a maximum in the first cycle. The unloading paths after a given strain are the same for all coatings and follow the same curve independent of the cycle number.

Finally, as shown in Figure 9, the energy absorption of neat PU is greater than PU + GNP and PU + GNP + SG for all cycles. It is noticeable that at the maximum strain while the maximum stress attained for PU is $107.9 \mathrm{MPa}$, for PU $+\mathrm{GNP}$, it is 77.4 MPa and for PU + GNP + SG, it is $71.5 \mathrm{MPa}$; hence, PU + GNP + SG experiences the least stresses during cyclic compressive loading. In our previous work, the erosion performance of these three coating under repeated rubber ball impact were investigated and the superiority of PU + GNP + SG was demonstrated. ${ }^{35}$

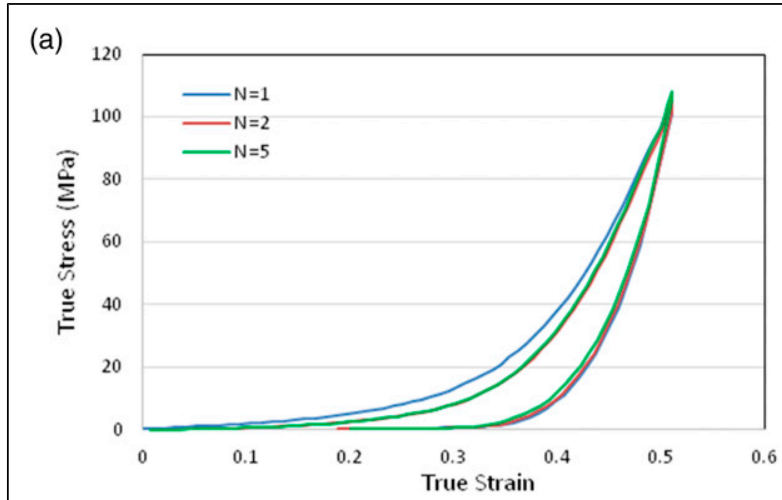

(c)

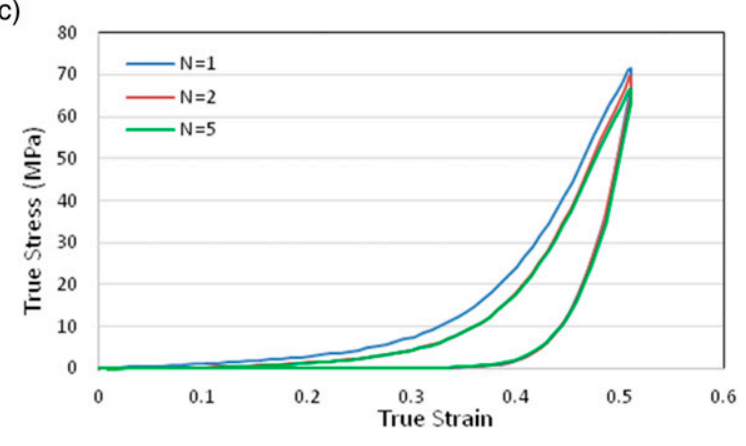

(b)

(d)
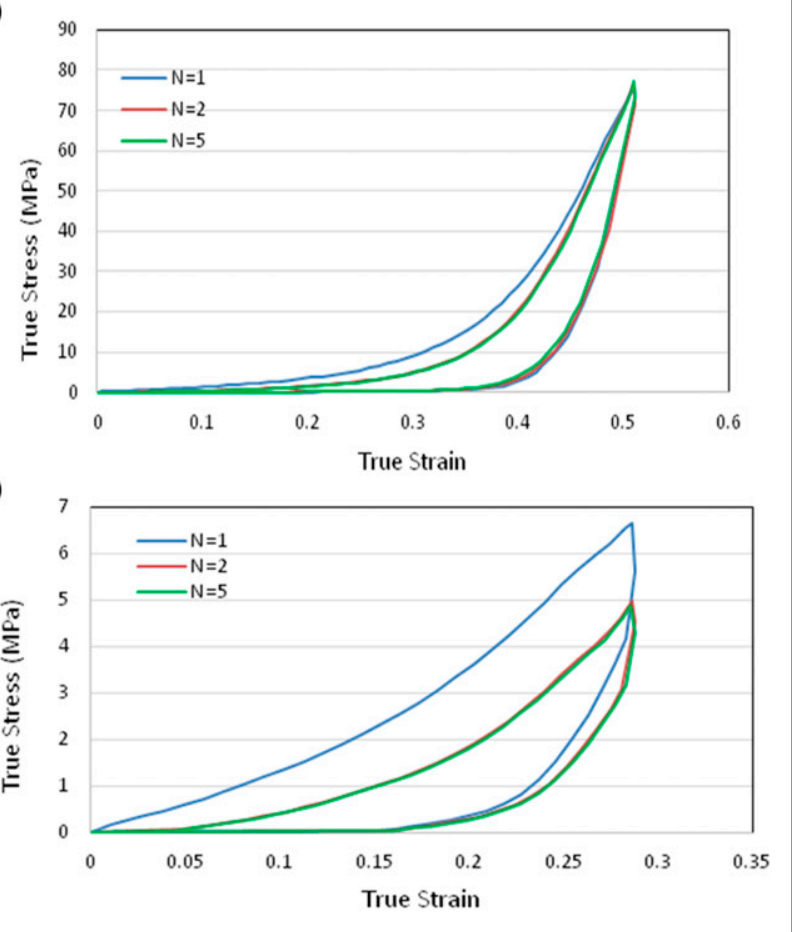

Figure 8. True stress-strain results of cyclic compression loading-unloading at $=0.1 \mathrm{~s}^{-1}$ for (a) neat PU at $\varepsilon_{\max }=0.5$, (b) PU + GNP at $\varepsilon_{\max }=0.5$, (c) PU + GNP + SG at $\varepsilon_{\max }=0.5$ and (d) PU + GNP + SG at $\varepsilon_{\max }=0.3$, respectively at RT.

Table 4. Results of the cyclic compression test on neat PU, PU + GNP and PU + GNP + SG at strain rate $=0.1 \mathrm{~s}^{-1}$.

\begin{tabular}{|c|c|c|c|c|c|}
\hline Material & Maximum applied strain & Cycle (N) & Residual strain $\varepsilon^{r}$ & Compressive strength ( $\mathrm{MPa})$ & Energy absorption $\left(\mathrm{kJ} / \mathrm{m}^{3}\right)$ \\
\hline \multirow[t]{6}{*}{ PU } & \multirow[t]{3}{*}{$\varepsilon_{\max }=0.5$} & I & $0.34 I$ & 104.8 & 6040 \\
\hline & & 2 & 0.339 & 105.2 & 4167 \\
\hline & & 5 & 0.326 & 107.9 & 3980 \\
\hline & \multirow[t]{3}{*}{$\varepsilon_{\max }=0.3$} & 1 & 0.205 & II.I & 708 \\
\hline & & 2 & 0.213 & 9.8 & 423 \\
\hline & & 5 & 0.216 & 8.6 & 389 \\
\hline \multirow[t]{6}{*}{$\mathrm{PU}+\mathrm{GNP}$} & \multirow[t]{3}{*}{$\varepsilon_{\max }=0.5$} & 1 & 0.385 & 75.9 & 5014 \\
\hline & & 2 & 0.364 & 76.2 & 3594 \\
\hline & & 5 & 0.358 & 77.4 & 3256 \\
\hline & \multirow[t]{3}{*}{$\varepsilon_{\max }=0.3$} & I & 0.224 & 7.9 & 333 \\
\hline & & 2 & 0.229 & 6.5 & 282 \\
\hline & & 5 & 0.237 & 6.2 & 281 \\
\hline \multirow[t]{6}{*}{$P U+G N P+S G$} & \multirow[t]{3}{*}{$\varepsilon_{\max }=0.5$} & I & 0.392 & 71.5 & 4759 \\
\hline & & 2 & 0.387 & 69.7 & 3310 \\
\hline & & 5 & 0.382 & 66.6 & 3344 \\
\hline & \multirow[t]{3}{*}{$\varepsilon_{\max }=0.3$} & I & 0.236 & 6.6 & 572 \\
\hline & & 2 & 0.242 & 5.0 & 270 \\
\hline & & 5 & 0.245 & 4.9 & 266 \\
\hline
\end{tabular}




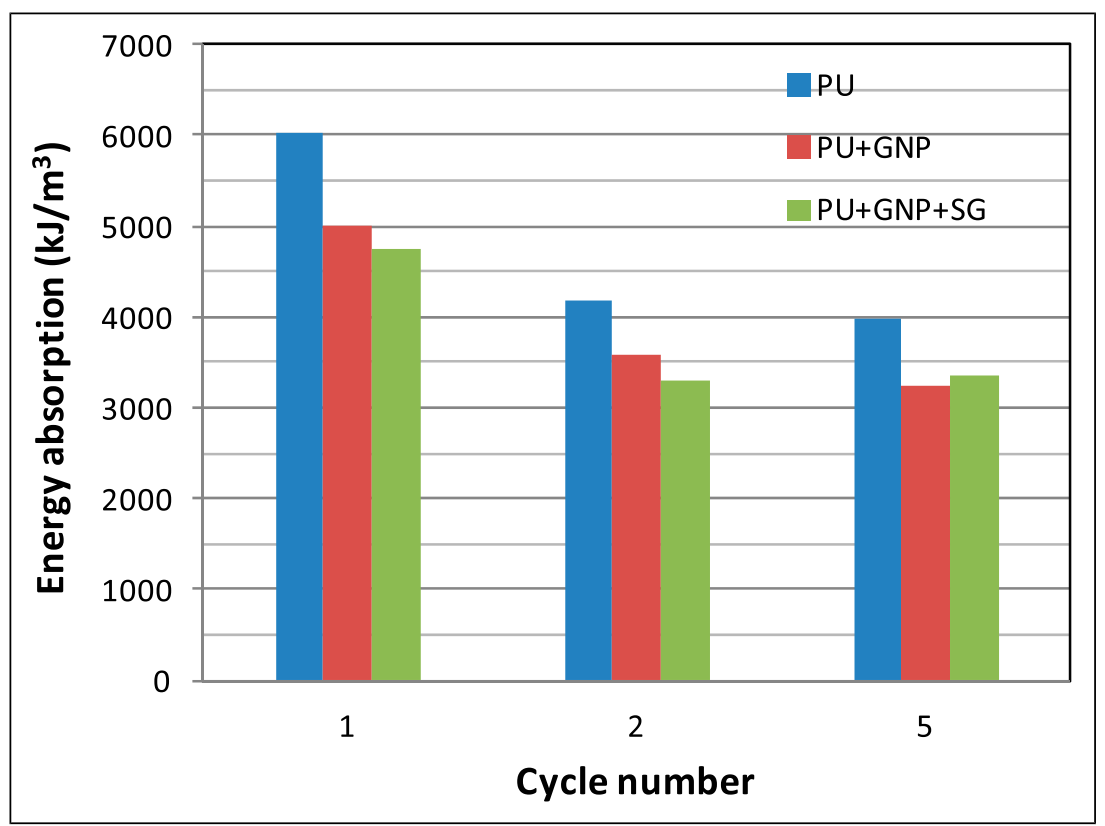

Figure 9. Comparison of energy absorption of PU, PU + GNP and PU + GNP + SG at $\varepsilon_{\max }=0.5$ and $\varepsilon=0.1 \mathrm{~s}^{-1}$.
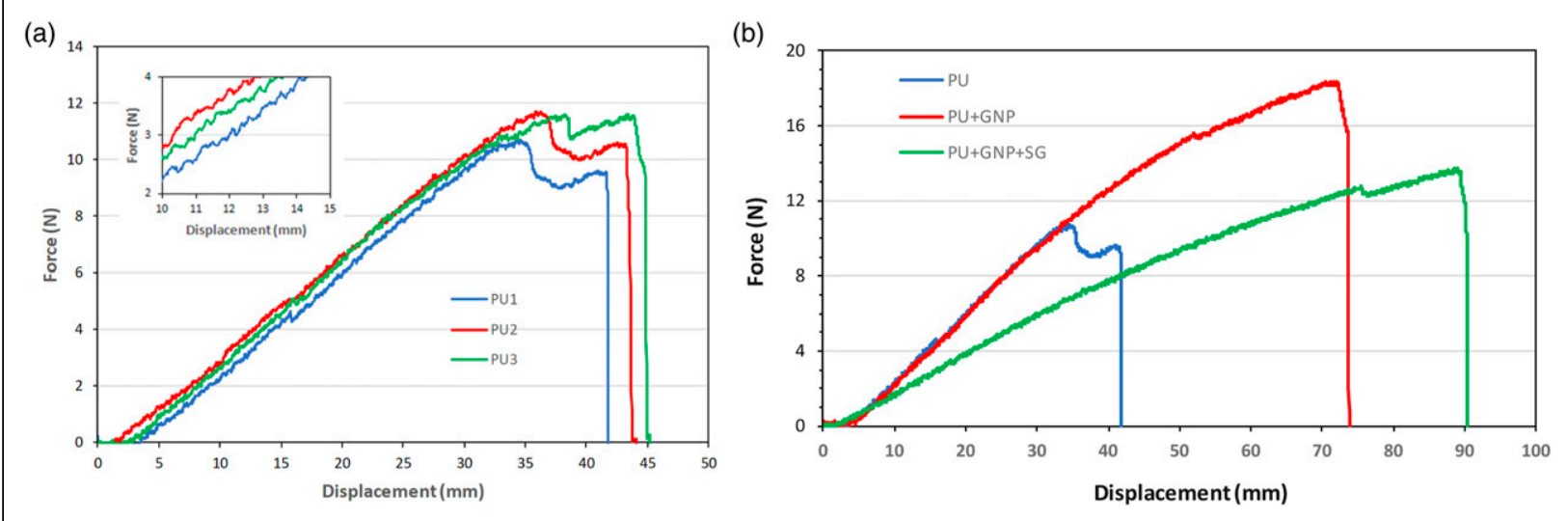

Figure 10. Tearing tests results of (a) three neat PU specimens (inset showing stick-slip) and (b) the PU, PU + GNP and PU + GNP + SG materials.

Table 5. Results of tearing test of neat PU, and PU + GNP and PU + GNP + SG nanocomposites.

\begin{tabular}{llll}
\hline Coating material & Ts $(\mathrm{kN} / \mathrm{m})$ & Elongation at break $(\mathrm{mm})$ & Tearing energy $(\mathrm{J})$ \\
\hline PU & $5.81 \pm 0.03$ & $44.3 \pm 0.7$ & $0.285 \pm 0.016$ \\
PU + GNP & $8.45 \pm 0.88$ & $68.5 \pm 4.2$ & $0.677 \pm 0.081$ \\
PU + GNP + SG & $6.51 \pm 0.26$ & $89.7 \pm 5.3$ & $0.707 \pm 0.045$ \\
\hline
\end{tabular}

\section{Tearing test results}

The results of the tearing tests on neat PU are shown in Figure 10(a). All three specimens show similar behaviour during the test. For all three specimens in the first $35 \mathrm{~mm}$ of elongation, the force was monotonically increased until the start of tearing, then crack growth occurred and the force decreased until the specimens completely tore into two pieces. Between displacements of 35 and $45 \mathrm{~mm}$, when crack growth occurred, there are slight differences in the behaviour of the specimens due to difference in the crack paths. The cracks tend to follow different preferred crack directions and they find the lowest resistance path for crack propagation. ${ }^{38}$ There were small fluctuations in the force during tearing tests. These variations are not noises from the instrument but rather caused by the stick-slip behaviour observed during fracture in the PU as can be seen in the inset of Figure 10(a). During stick-slip, the minimum force occurs when the crack extends, and the maximum represents crack arrest. The interval of these fluctuations relates to the morphology and micro mechanism of the polymer material, such as the polymer chain alignment, arrangement and distribution of crystalline. ${ }^{38}$ 


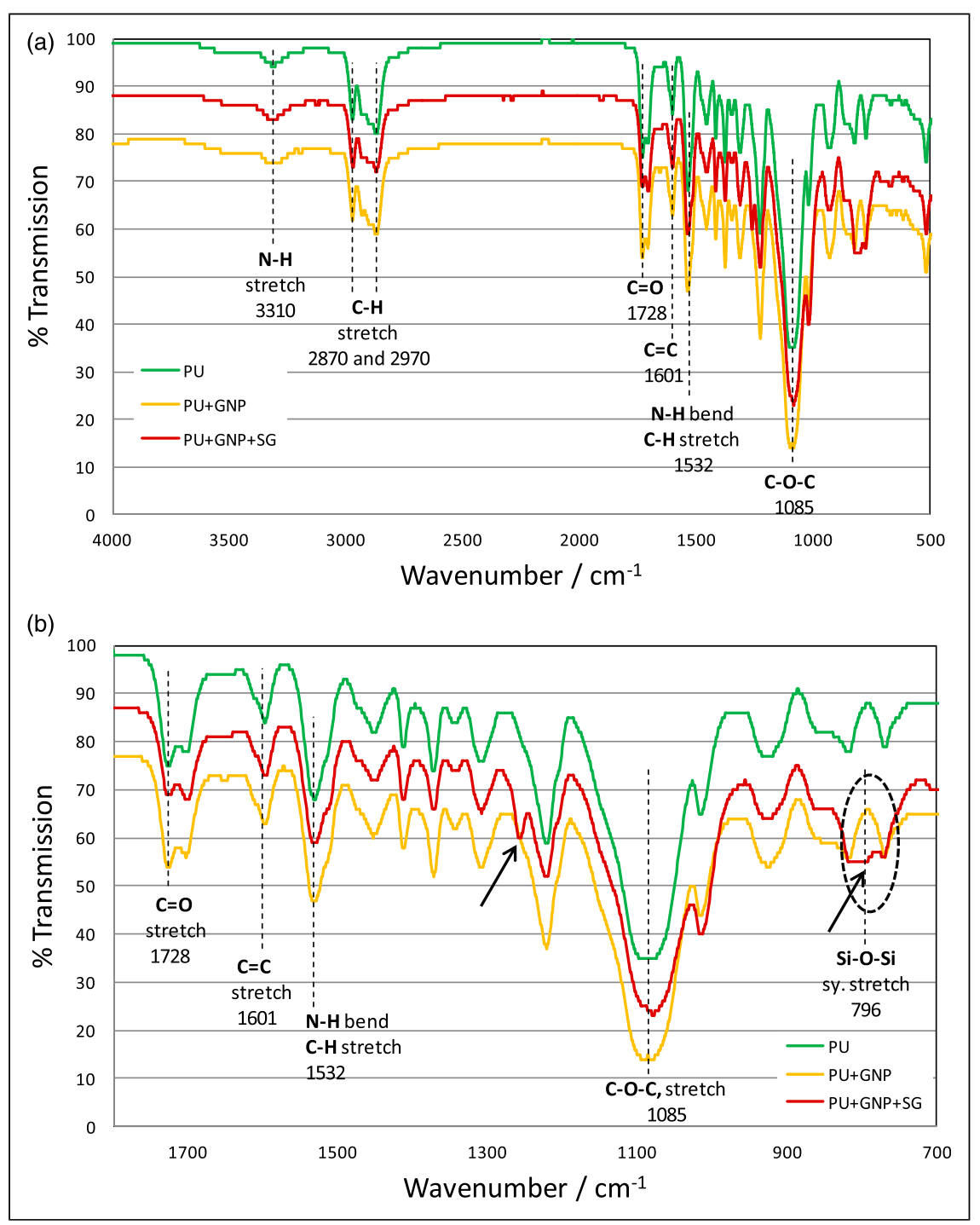

Figure I I. FTIR spectra of PU, PU + GNP and PU + GNP + SG at wavenumber range of (a) $4000-500 \mathrm{~cm}^{-1}$ and (b) $1800-1700 \mathrm{~cm}^{-1}$.

The results of the tearing tests of PU, PU + GNP and PU + GNP + SG are compared in Figure 10(b). On average, the tearing strength of PU + GNP material is $45 \%$ higher and its elongation at break 55\% higher than neat PU values. Also on average, the tearing strength of PU + GNP ++ SG material is $12 \%$, higher than neat PU but $30 \%$ less than PU + GNP. PU + GNP + SG elongation at break is $102 \%$ higher than neat PU value and $31 \%$ more than for PU + GNP. The tearing energy of PU + GNP nanocomposites is $137 \%$ higher than the neat PU and for PU + GNP + SG it is $148 \%$ higher than neat PU and $4.4 \%$ more than $\mathrm{PU}+$ GNP. A summary of the tearing tests results for the PU and its two nanocomposites together with $95 \%$ confidence levels are presented in Table 5 .

\section{Microstructural analysis}

Figure 11 shows the infrared spectra of PU, PU + GNP, and PU + GNP + SG. All three FTIR spectra displayed characteristic peaks due to the key functional groups of polyurethane: N-H stretch at $3250 \mathrm{~cm}^{-1}$, C-H stretches in $2950-2800 \mathrm{~cm}^{-1}$ region and a carbonyl group stretch at $1700 \mathrm{~cm}^{-1}$. In the fingerprint region $\left(1500-500 \mathrm{~cm}^{-1}\right)$, the only significant difference observed between PU and the modified PU is an additional peak around $800 \mathrm{~cm}^{-1}$ in the spectrum of PU $+\mathrm{GNP}+\mathrm{SG}$. This may be attributed to the symmetric stretching vibration of a $\mathrm{Si}-\mathrm{O}-\mathrm{Si}{ }^{39}$

The general scheme for the preparation of PU nanocomposites and their interaction with the GNP is presented in Figure 12. Carboxyl functionalised GNP create hydrogen bonding with the PU backbone chain, and hence stronger interface of GNP and PU backbone chain, resulting in improvement in mechanical properties of PU. This was supported by the field emission scanning electron microscope (FESEM) studies. FESEM images of the PU and its composites are presented in Figure 13 together with energy-dispersive X-ray spectroscopy (EDX) and elemental mapping of the samples. The SEM images of PU and PU + GNP clearly indicate that the incorporation of f-GNP into the PU polymer did not significantly alter the surface morphology and there were no appreciable evidences of graphene sheets appearing on the surface, suggesting the homogeneous dispersion of f-GNP in the PU matrix. This could be due to the strong interaction of f-GNP carboxylic groups with the 


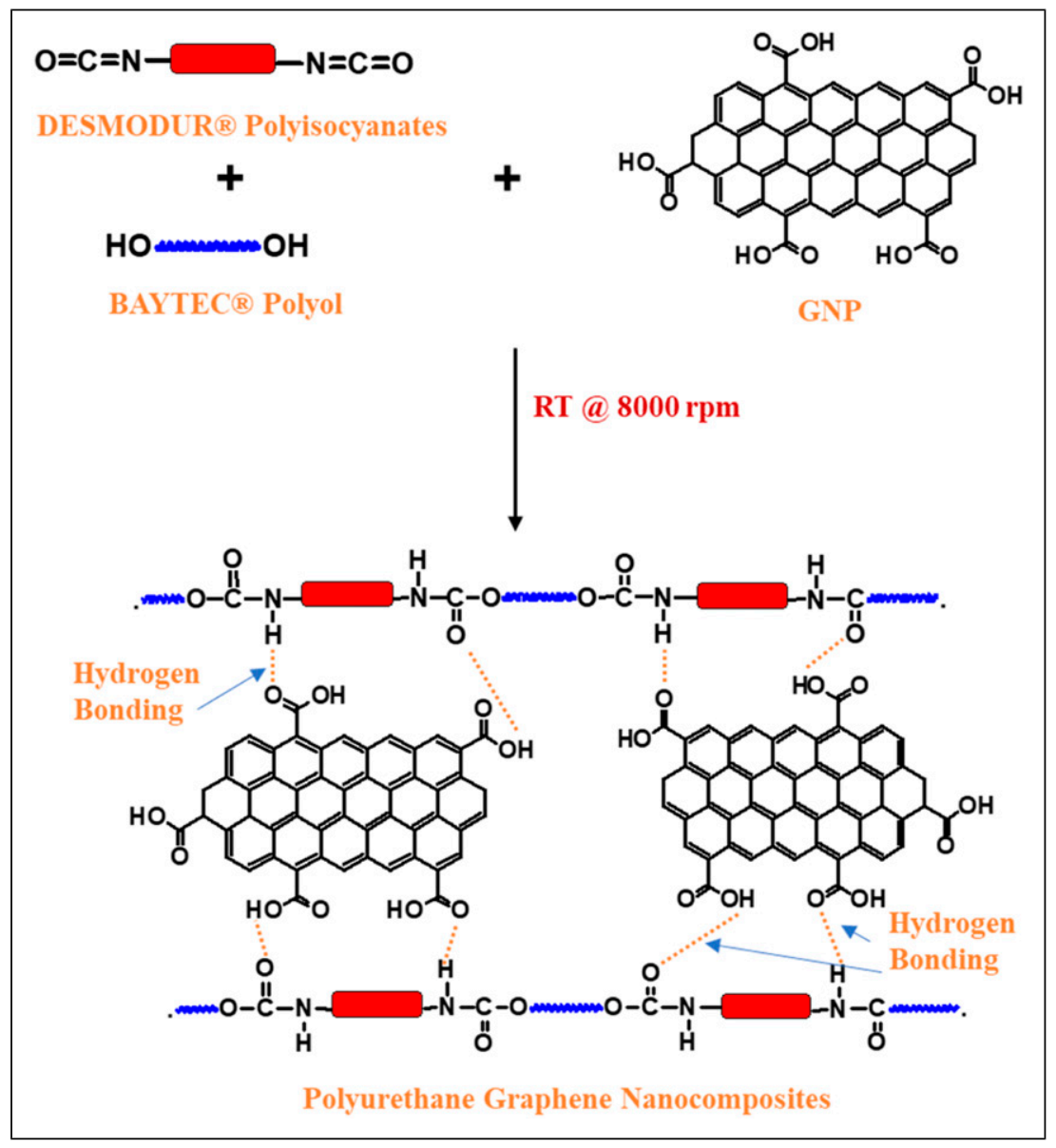

Figure 12. General scheme for the preparation of PU and its GNP composites.

urethane functional groups in PU via hydrogen bonding as shown in Figure 12. The strong hydrogen bonding leads to the uniform dispersion of f-GNP and can avoid leaching of graphene sheets out of the PU matrix over time.

Interestingly, PU + GNP + SG displayed a smoother surface than PU and PU + GNP. This could be due to the in-situ polymerisation technique adopted in the preparation of $\mathrm{PU}+\mathrm{GNP}+\mathrm{SG}$. The silica particles are initially well dispersed in the polyisocynates and are then transferred to the f-GNP-polyol mixture to initiate the polymerisation; thus, the polymerisation initiates around the silica and f-GNP nanoparticles, which facilitates the strong interactions between the nanoparticles and polymer chains. This in turn prevents the aggregation of nanoparticles and helps the homogeneous dispersion of nanomaterials within the PU matrix. Moreover, research has shown that grafting hydrophobic moieties onto the silica surface can enhance the silica's miscibility with polymer components due to its reduced hydrophilicity and enhanced interfacial interaction with the PU matrix. ${ }^{40,41}$ Furthermore, the presence of carboxylic groups on f-GNP can improve the dispersibility via hydrogen bonding. The uniform and continuous dispersion of silica nanoparticles in the PU matrix was further confirmed in the EDX and elemental mapping, as shown in Figure 13.

\section{Water droplet contact angle and surface energy of the coatings}

The variation of water contact angle (CA) with respect to time for PU and its nanocomposites are presented in Figure 14. The results show that the water CA of PU is between 56 and 57. This indicates the slightly hydrophobic property of the neat PU. The low hydrophobicity of PU is due to the presence of a large number of surface polar urethane functional groups which can interact with polar water molecules. However, addition of f-GNP nanoparticles to the PU increased hydrophobicity (CA between 70 and 80). The two-dimensional f-GNP nanoparticles possess a high surface area, and are highly hydrophobic due to grapheme's non-polar nature and only a small concentration of carboxylic groups at the edges. The small addition of $0.5 \mathrm{wt} \%$ of f-GNP covers a large surface area within PU matrix and improves the overall hydrophobicity. Further, the addition of hydrophobic silica along with f-GNP significantly contributes to the increase in the overall hydrophobicity of the coating. The CA of PU increased from 56 to around 110 with the addition of $0.5 \mathrm{wt} \%$ f-GNP and $1 \mathrm{wt} \%$ hydrophobic silica. The hydrophobic functionalized silica improves the compatibility as well dispersibility in the PU matrix. The silica nanoparticles are easily adsorbed on the graphene surface which further improves their dispersibility as observed in the elemental mapping shown in Figure 13. The addition of hydrophobic nanoparticles $(0.5 \mathrm{wt} \% \mathrm{GNP}+1 \mathrm{wt} \%$ sol-gel $)$ and their homogeneous dispersion enhance the hydrophobicity of the PU matrix. 


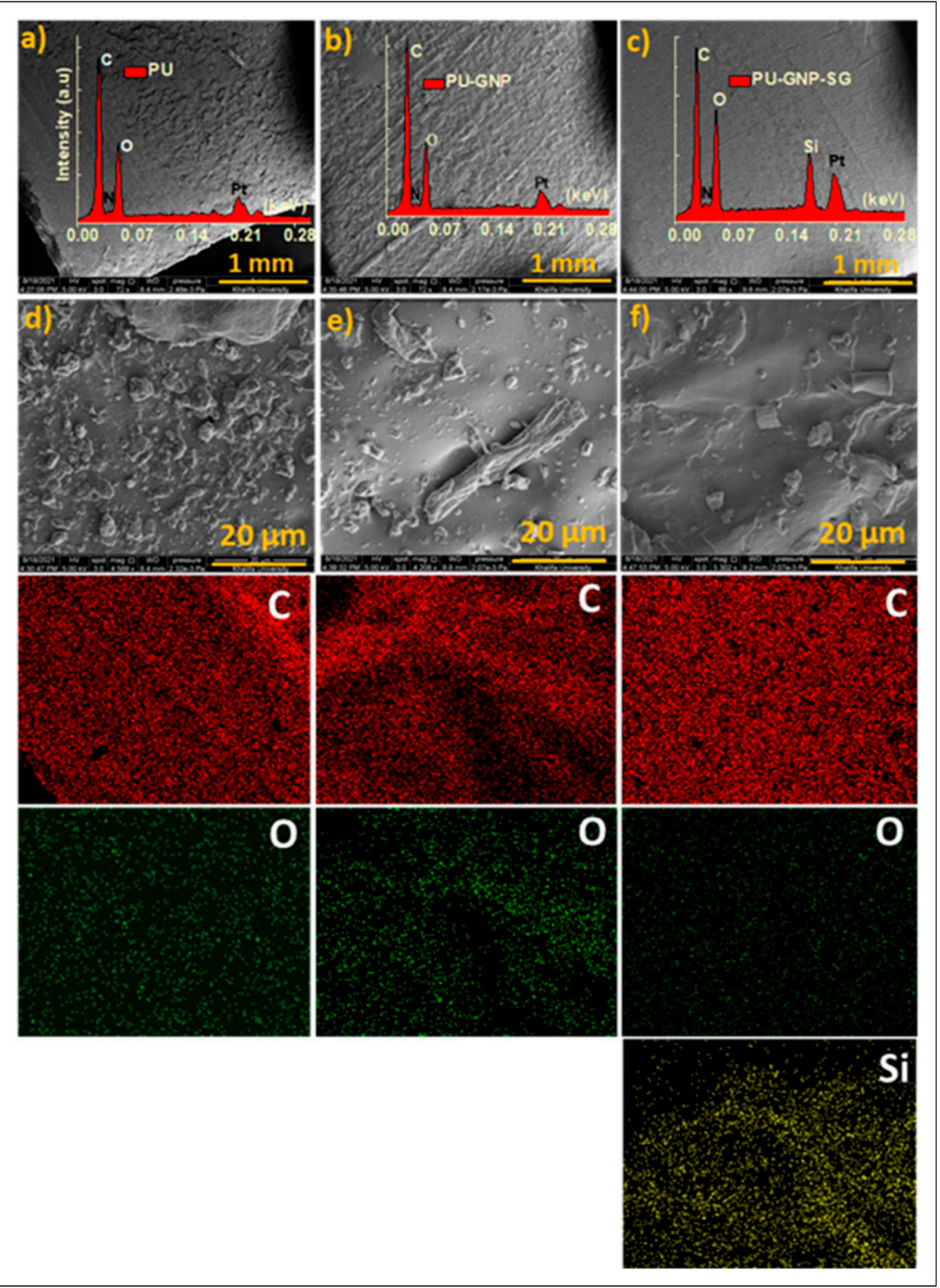

Figure 13. The FESEM of top surface of ( $a, d) P U,(b, e) P U+G N P$ and (c, $f$ ) PU + GNP + SG, at different magnification. Insight image on (a) to (c) shows the corresponding EDX mapping and the bottom columns correspond to the respective elemental mapping.

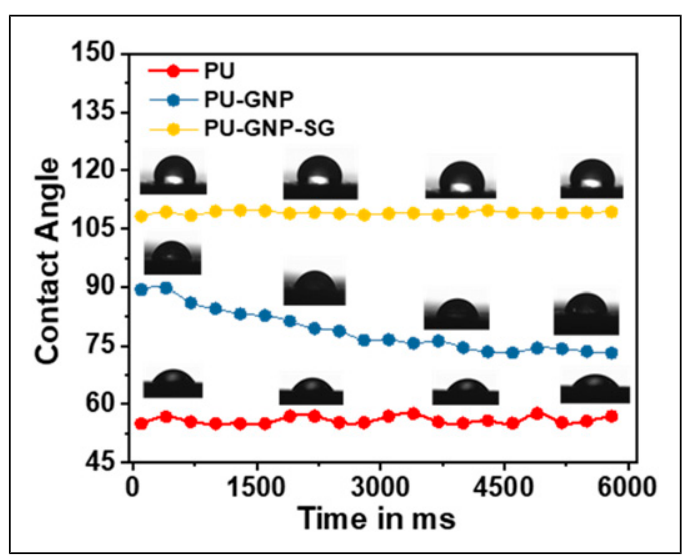

Figure 14. The comparison of static DI water contact angle (CA) of the GFRP surfaces coated with PU, PU + GNP and PU + GNP + SG at different interval of time. 
Moreover, the surface free energy, which was determined from the initial static DI CA values, followed an opposite trend when compared to the static DI CA. The calculated surface free energy of pure PU was around $114.55 \mathrm{~mJ} \cdot \mathrm{m}^{-2}$; however, with the addition of the $f$-GNP into the PU, the surface energy decreased to $73.36 \mathrm{~mJ} \cdot \mathrm{m}^{-2}$. Furthermore, the addition of hydrophobic silica significantly reduced the surface free energy to $50.06 \mathrm{~mJ} \cdot \mathrm{m}^{-2}$ in the PU $+\mathrm{GNP}+\mathrm{SG}$ material. The decrease in surface free energy suggests the superior water repellency of the PU modified coatings which could improve the weather resistant property.

\section{Conclusions}

Polyurethanes have low elastic modulus and tensile strength, capable of large deformation. The mechanical properties of PU have been improved by incorporating functionalised graphene nanoplatelets (f-GNP) and silica-based sol-gel in PU matrices.

Tensile, monotonic and cyclic compressive and tearing tests have been conducted. The results showed that the mechanical response of PU and its modified ones depend strongly on temperature, strain rate and nanoparticles loading. The PU + GNP + SG nanocomposite with $0.5 \mathrm{wt} \%$ GNP and $1 \mathrm{wt} \%$ SG loadings has the highest elongation at break, UTS, modulus of toughness and second highest Young's modulus in tensile tests.

The cyclic compression tests revealed that the maximum stress at maximum strain of 0.5 for PU is $107.9 \mathrm{MPa}$, for PU + GNP is $77.4 \mathrm{MPa}$ and for PU + GNP + SG is $71.5 \mathrm{MPa}$. This indicates PU + GNP + SG experiences the least stresses during cyclic compressive loading, beneficial to repeated compressive impact by rain droplets as observed in our previous work. ${ }^{35}$

Tearing test results showed that the PU + GNP nanocomposite has the highest tearing strength and $\mathrm{PU}+\mathrm{GNP}+\mathrm{SG}$ has the highest elongation at break. The PU + GNP + SG nanocomposite has much higher value for Young's modulus 95\%, tensile strength $115 \%$, modulus of toughness (124\%) and elongation at break (102\%) relative to the neat PU at room temperature. In addition, the tearing energy for both modified PU nanocomposites was higher than the neat PU (137\% increase for PU + GNP and $148 \%$ increase for PU + GNP + SG).

The developed PU coatings were primarily intended for leading edge erosion protection of wind turbine blades. The erosion tests of the developed coatings have been performed with rubber balls; water-jet erosion tests will be carried out in the near future. In addition, these coatings have properties that might be exploited for many other applications such as for roof coatings in anticorrosive/erosion resistance and for line-marking paints. In addition, hydrophobicity of the developed coatings enables surfaces to clean themselves by the rolling of water droplets on the surfaces.

\section{Acknowledgements}

The authors HH and AD are grateful to Dr Fanya Ismail from SGMA (Sol-Gel Materials \& Applications Ltd) Company, UK, for in-kind supply of sol-gel material and assistance from mechanical testing technician Dean Wells at Kingston University. The authors LM and NFJJ gratefully acknowledge the financial support of the Innovation Foundation of Denmark in the framework of the Grand Solutions project DURALEDGE, Durable leading edges for high tip speed wind turbine blades, File nr.: 8055-00012A.

\section{Declaration of conflicting interests}

The author(s) declared no potential conflicts of interest with respect to the research, authorship, and/or publication of this article.

\section{Funding}

The author(s) disclosed receipt of the following financial support for the research, authorship, and/or publication of this article: This work was supported by the Innovation Foundation of Denmark, File nr.: 8055-00012A.

\section{ORCID iDs}

Nicolai Frost-Jensen Johansen (D) https://orcid.org/0000-0001-9986-7162

Homayoun Hadavinia (D) https://orcid.org/0000-0002-2324-357X

\section{References}

1. Sareen A, Sapre CA and Selig MS. Effects of leading edge erosion on wind turbine blade performance. Wind Energy. 2014; 17(10): $1531-1542$.

2. Han W, Kim J and Kim B. Effects of contamination and erosion at the leading edge of blade tip airfoils on the annual energy production of wind turbines. Renew Energy. 2018; 115: 817-823.

3. Wilcox BJ, White EB and Maniaci DC. Roughness Sensitivity Comparisons of Wind Turbine Blade Sections. Report No. SAND201711288. California, CA: Sandia National Laboratories: 2017.

4. Krog Kruse E, Sørensen NN and Bak C. A two dimensional quantitative parametric investigation of simplified surface imperfections on the aerodynamic characteristics of a NACA 633418 airfoil. Wind Energy 2021; 24(4): 310-322.

5. Dashtkar A, Hadavinia H, Sahinkaya MN, et al. Rain erosion-resistant coatings for wind turbine blades - a review. Polym Polym Compos 2019; 27(8): 443-475.

6. Keegan MH, Nash DH and Stack MM. On erosion issues associated with the leading edge of wind turbine blades. J Phys Appl Phys 2013; 46(38): 383001. 
7. Slot HM., Gelinck ERM, Rentrop C, et al. Leading edge erosion of coated wind turbine blades: review of coating life models. Renew Energy 2015; 80: 837-848.

8. Herring R, Dyer K, Martin F, et al. The increasing importance of leading edge erosion and a review of existing protection solutions. Renew Sustainable Energy Rev 2019; 115: 109382.

9. Kojio K, Nozaki S, Takahara A, et al. Influence of chemical structure of hard segments on physical properties of polyurethane elastomers: a review. J Polym Res 2020; 27: 140.

10. Yilgör I, Yilgör E, Wilkes GL, et al. Critical parameters in designing segmented polyurethanes and their effect on morphology and properties: a comprehensive review. Polymer 2015; 58: A1-A36.

11. Qi HJ and Boyce MC. Stress-strain behavior of thermoplastic polyurethanes. Mech Mater 2005; 37(8): 817-839.

12. Mishnaevsky L, Jr. Toolbox for optimizing anti-erosion protective coatings of wind turbine blades: overview of mechanisms and technical solutions. Wind Energy 2019; 22(11): 1636-1653.

13. Domun N, Hadavinia H, Zhang T, et al. Improving fracture toughness and strength of epoxy using nanomaterials - a review of current status. Nanoscale 2015; 7(23): 10294-10329.

14. Wang X, Hu Y, Song L, et al. In situ polymerization of graphene nanosheets and polyurethane with enhanced mechanical and thermal properties. J Mater Chem 2011; 21: 4222.

15. Dashtkar A, Hadavinia H, Barros-Rodriguez J, et al. Quantifying damping coefficient and attenuation at different frequencies for graphene modified polyurethane by drop ball test. Polym Test 2021; 100: 107267.

16. Chung YC, Khiem ND and Chun BC. Characterization of a polyurethane copolymer covalently linked to graphite and the influence of graphite on electric conductivity. J Compos Mater 2014; 49(14): 1689-1703.

17. Malaki M, Hashemzadeh Y and Karevan M. Effect of nano-silica on the mechanical properties of acrylic polyurethane coatings. Prog Org Coat 2016; 101: 477-485.

18. Petrovic ZS, Javni I, Waddon A, et al. Structure and properties of polyurethane-silica nanocomposites. J Appl Polym Sci 2000; 76(2): $133-151$

19. Chung YC, Chung KH, Choi JW, et al. Preparation of hybrid polyurethane-silica composites by a lateral sol-gel process using tetraethyl orthosilicate. J Compos Mater 2018; 52(2): 159-168.

20. Syamsundar C, Chatterjee D, Kamaraj M, et al. Erosion characteristics of nanoparticle-reinforced polyurethane coatings on stainless steel substrate. J Mater Eng Perform 2015; 24(4): 1391-1405.

21. Mills DJ, Jamali SS and Paprocka K. Investigation into the effect of nano-silica on the protective properties of polyurethane coatings. Surf Coat Technol 2012; 209: 137-142.

22. Kotnarowska D, Przerwa M and Wojtyniak M. Effect of epoxy and polyurethane coating modification with nanofillers on their resistance to erosive wear. Vibroengineering 2011; 13: 870-875.

23. Pokharel P, Pant B, Pokhrel K, et al. Effects of functional groups on the graphene sheet for improving the thermomechanical properties of polyurethane nanocomposites. Composites Eng 2015; 78: 192-201.

24. Tarasov AE, Anokhin DV, Propad YV, et al. Synergetic effect of fullerene and graphene oxide nanoparticles on mechanical characteristics of cross-linked polyurethanes under static and dynamic loading. J Compos Mater 2019; 53(26-27): 3797-3805.

25. Xia H and Song M. Preparation and characterization of polyurethane-carbon nanotube composites. Soft Matter 2005; 1: 386-394.

26. Tayfun U, Kanbur Y, Abacı U, et al. Mechanical, electrical, and melt flow properties of polyurethane elastomer/surface-modified carbon nanotube composites. J Compos Mater 2017; 51(14): 1987-1996.

27. Guo S, Zhang C, Wang W, et al. Preparation and characterization of polyurethane/multiwalled carbon nanotube composites. Polym Polym Compos 2008; 16: 501-507.

28. Kumar D, Bansal SA, Kumar N, et al. Two-step synthesis of polyurethane/multi-walled carbon nanotubes polymer composite to achieve high percentage particle reinforcement for mechanical applications. J Compos Mater 2021; 55(21): 2877-2885.

29. Li Y, Jiao H, Pan G, et al. Mechanical and damping properties of carbon nanotube-modified polyisobutylene-based polyurethane composites. J Compos Mater 2016; 50(7): 929-936.

30. Eivazi Zadeh Z, Solouk A, Shafieian M, et al. Electrospun polyurethane/carbon nanotube composites with different amounts of carbon nanotubes and almost the same fiber diameter for biomedical applications. Mater Sci Eng C 2021; 118: 111403.

31. Moghim MH and Zebarjad SM. Tensile properties and deformation mechanisms of PU/MWCNTs nanocomposites. Polym Bull 2017; 74: $4267-4277$.

32. Alberto M, Iliut M, Pitchan MK, et al. High-grip and hard-wearing graphene reinforced polyurethane coatings. Composites Part B: Eng 2021; 213: 108727.

33. Qiao X, Chen R, Zhang H, et al. Outstanding cavitation erosion resistance of hydrophobic polydimethylsiloxane-based polyurethane coatings. J Appl Polym Sci 2019; 136(25): 47668.

34. Rihayat T, Saari M, Mahmood MH, et al. Mechanical characterisation of polyurethane/clay nanocomposites. Polym Polym Compos 2007; 15(8): 647-652.

35. Frost-Jensen Johansen N, Mishnaevsky L Jr., Dashtkar A, et al. Nanoengineered graphene-rnforced coating for leading edge protection of wind turbine blades. Coatings 2021; 11(9): 1104.

36. ISO 34-1 2015 Standard. Rubber, vulcanized or thermoplastic-Determination of tear strength. Part 1:Trouser, Angle and Crescent Test Pieces. 2015.

37. Ibrahim Y, Wadi VS, Ouda M, et al. Highly selective heavy metal ions membranes combining sulfonated polyethersulfone and selfassembled manganese oxide nanosheets on positively functionalized graphene oxide nanosheets. Chem Eng J 2022; $428(15): 131267$. 
38. Andreasson E, Mehmood N and Kao-Walter S. Trouser tear tests of two thin polymer films. In: 13th International Conference on Fracture, Beijing, 16-21 June 2013; 2013.

39. Pinto PR, Mendes LC, Dias ML, et al. Synthesis of acrylic-modified sol-gel silica. Colloid Polym Sci 2006; 284: 529-535.

40. Wu Z, Wang H, Tian X, et al. Surface and mechanical properties of hydrophobic silica contained hybrid films of waterborne polyurethane and fluorinated polymethacrylate. Polymer 2014; 55: 187-194.

41. Khani MM, Woo D, Mumpower EL, et al. Poly(alkyl methacrylate)-grafted silica nanoparticles in polyethylene nanocomposites. Polymer 2017; 109: 339-348. 